\title{
Influenza-specific lung-resident memory T cells are proliferative and polyfunctional and maintain diverse TCR profiles
}

\author{
Angela Pizzolla, ${ }^{1}$ Thi H.O. Nguyen, ${ }^{1}$ Sneha Sant, ${ }^{1}$ Jade Jaffar, ${ }^{2,3}$ Tom Loudovaris, ${ }^{4}$ Stuart I. Mannering, ${ }^{4}$ Paul G. Thomas, ${ }^{5}$ \\ Glen P. Westall, ${ }^{2,3}$ Katherine Kedzierska, ${ }^{1}$ and Linda M. Wakim ${ }^{1}$ \\ 'Department of Microbiology and Immunology, The University of Melbourne, Peter Doherty Institute for Infection and Immunity, Melbourne, Victoria, Australia. ${ }^{2}$ Lung Transplant Service, Alfred Hospital, \\ Melbourne, Victoria, Australia. ${ }^{3}$ Department of Medicine, Monash University, Melbourne, Victoria, Australia. ${ }^{4}$ Immunology and Diabetes Unit, St. Vincent's Institute of Medical Research, Fitzroy, Victoria, \\ Australia. ${ }^{5}$ Department of Immunology, St. Jude Children's Research Hospital, Memphis, Tennessee, USA
}

\begin{abstract}
The human lung harbors a large population of resident memory T cells (Trm cells). These cells are perfectly positioned to mediate rapid protection against respiratory pathogens such as influenza virus, a highly contagious respiratory pathogen that continues to be a major public health burden. Animal models show that influenza-specific lung CD8+ Trm cells are indispensable for crossprotection against pulmonary infection with different influenza virus strains. However, it is not known whether influenza-specific CD8+ Trm cells present within the human lung have the same critical role in modulating the course of the disease. Here, we showed that human lung contains a population of CD8+ Trm cells that are highly proliferative and have polyfunctional progeny. We observed that different influenza virus-specific CD8 ${ }^{+} \mathrm{T}$ cell specificities differentiated into Trm cells with varying efficiencies and that the size of the influenza-specific CD8 ${ }^{+} \mathrm{T}$ cell population persisting in the lung directly correlated with the efficiency of differentiation into Trm cells. To our knowledge, we provide the first ex vivo dissection of paired T cell receptor (TCR) repertoires of human influenza-specific CD8 ${ }^{+}$Trm cells. Our data reveal diverse TCR profiles within the human lung Trm cells and a high degree of clonal sharing with other CD8 ${ }^{+} \mathrm{T}$ cell populations, a feature important for effective $T$ cell function and protection against the generation of viral-escape mutants.
\end{abstract}

\section{Introduction}

Influenza A viruses cause substantial morbidity and mortality worldwide. Vaccination is considered to be the best way to prevent human influenza disease. Current antibody-based vaccines are highly effective in the control of influenza virus infection. These vaccines elicit humoral immunity directed toward viral surface glycoproteins. However, due to antigenic drift, these surface glycoproteins rapidly mutate, and hence the humoral immunity established against one influenza virus strain is unlikely to protect against subsequent infections with distinct influenza strains. Thus, it is necessary to reformulate vaccines annually to match and protect against the circulating seasonal virus. Furthermore, antibody-based vaccines also offer no protection during a pandemic outbreak, where the emergence of novel viruses can have a devastating impact on global health (i.e., 1918-1919 H1N1 pandemic, >40 million deaths; 2013 H7N9 pandemic in China [ref. $1]$, mortality rate $>30 \%$ ). The induction of virus-specific memory $\mathrm{CD}^{+} \mathrm{T}$ cell immunity is an effective means of inducing long-lived crossprotection against different influenza strains (2-4). As CD8 ${ }^{+}$ $\mathrm{T}$ cell immunity is largely directed toward internal viral proteins

Authorship note: A. Pizzolla, T.H.O. Nguyen, and S. Sant contributed equally to this work. L.M. Wakim and K. Kedzierska are co-senior authors.

Conflict of interest: The authors have declared that no conflict of interest exists.

Submitted: August 18, 2017; Accepted: November 14, 2017

Reference information: J Clin Invest. 2018;128(2):721-733.

https://doi.org/10.1172/JCI96957. that are highly conserved across different influenza viruses, these $\mathrm{T}$ cells have the potential to protect against a range of influenza virus strains, including those with pandemic potential.

Recent studies have demonstrated that $\mathrm{CD}^{+} \mathrm{T}$ cell immunity modulates the course of influenza infection in humans. Specifically, it was shown that influenza-specific $\mathrm{CD} 8^{+} \mathrm{T}$ cells generated by seasonal influenza infection can promote influenza virus elimination and host recovery, leading to a milder disease $(5,6)$, and that the recovery from severe influenza infection (H7N9 avain strain) is associated with robust recall of preexisting $\mathrm{CD}^{+} \mathrm{T}$ cell memory (7). Memory $\mathrm{CD}^{+} \mathrm{T}$ cells can be broadly divided into 3 subsets: 2 highly mobile circulating memory $\mathrm{CD} 8^{+} \mathrm{T}$ cell subsets, termed central and effector memory T cells (Tem cells), and a sessile memory $\mathrm{T}$ cell pool that is resident within peripheral tissues. While it was unclear from these clinical studies which memory $\mathrm{T}$ cell subset was responsible for the observed protection, growing evidence from animal models shows that not all memory $\mathrm{CD}^{+} \mathrm{T}$ cell subsets are equally protective against influenza virus infection, with only the tissue resident memory (Trm) subset being absolutely indispensable for crossprotection against different strains of influenza virus $(8,9)$.

Previous studies have reported that the human lung harbors a large population of memory $\mathrm{T}$ cells - a number comparable to the number of $\mathrm{T}$ cells present within human blood (10). Characterization of Trm cells that reside within human lung tissue revealed that these cells constitutively express deployment-ready mRNAs encoding effector molecules, which is reflective of these cells 
A
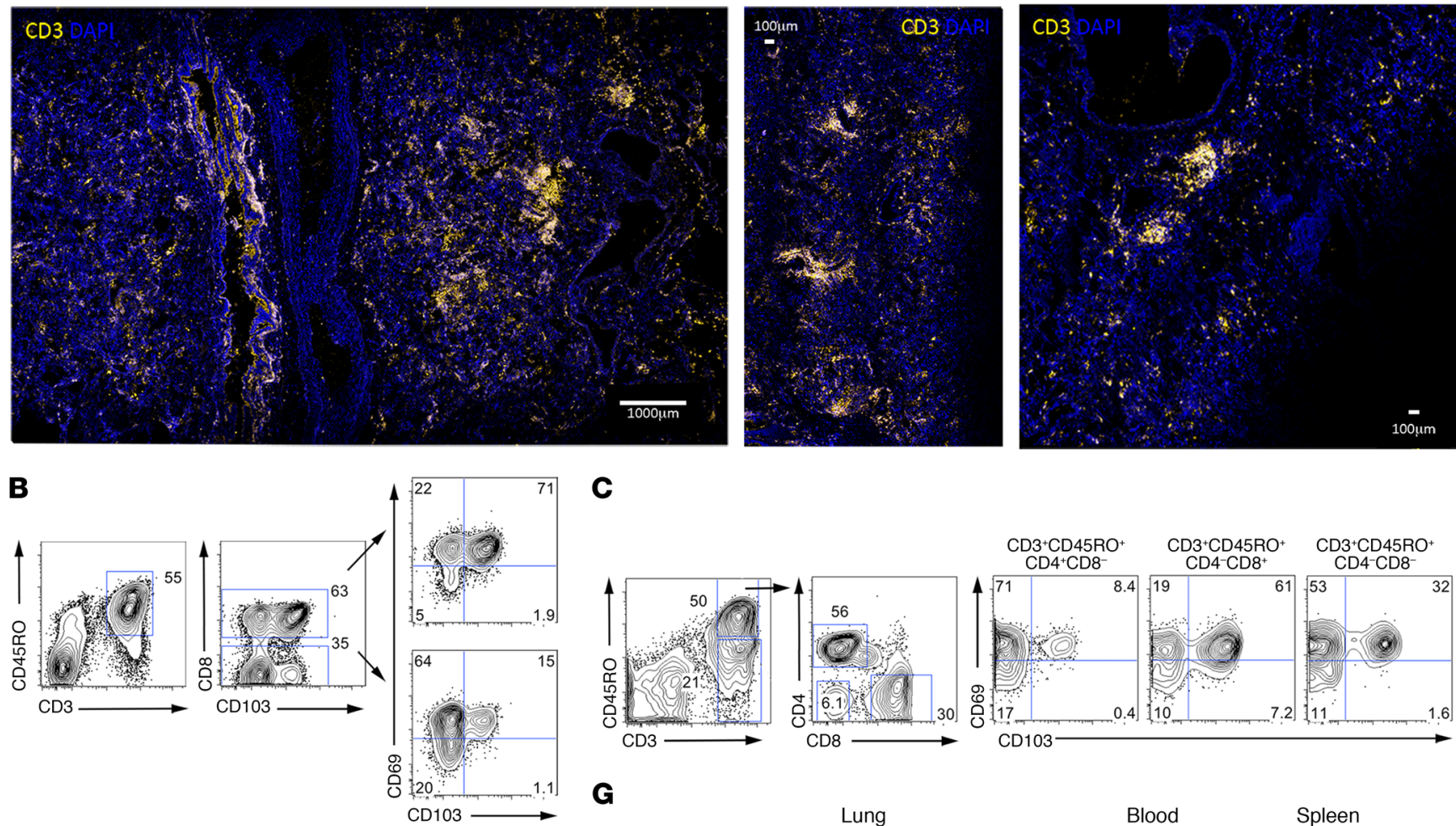

C
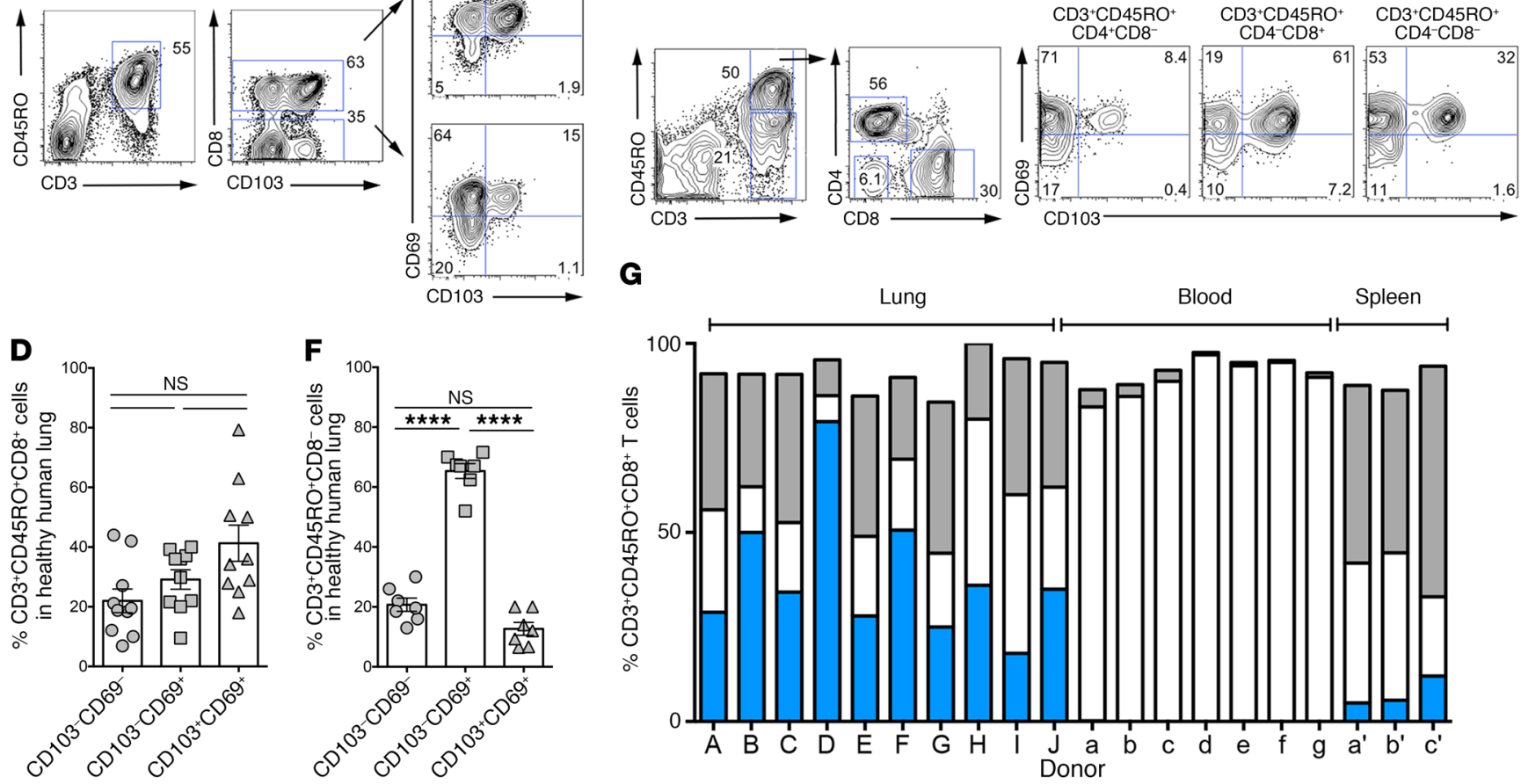

G
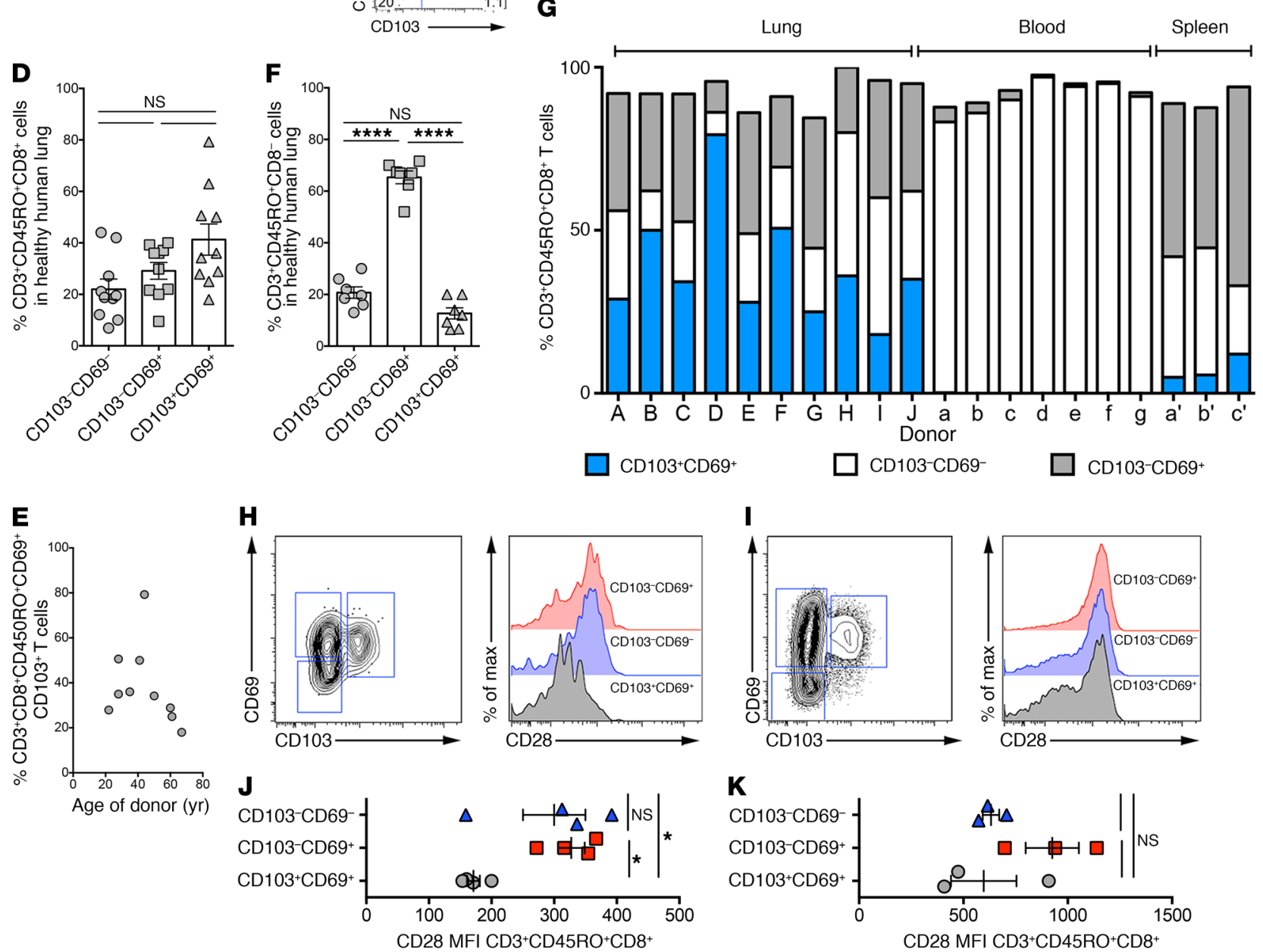
Figure 1. Location and phenotype of resident memory $T$ cells in healthy human lung. (A) Microscopy of human lung tissue with CD3 (yellow) and DAPI staining. Scale bars: $1000 \mu \mathrm{m}$. (B) Flow cytometry profiles depicting the level of expression of CD103 and CD69 on memory CD8 ${ }^{+}$(CD45RO+ $\left.\mathrm{CD}^{+} \mathrm{CD}^{+}\right) \mathrm{T}$ cells isolated from human lung. (C) Flow cytometry profiles depicting the level of expression of $\mathrm{CD} 103$ and $\mathrm{CD} 69$ on memory $\mathrm{CD} 8^{+}, \mathrm{CD}^{+}$, and CD4-CD8- (CD45RO+CD3') T cells isolated from human lung. (D) The percentages of antigen-experienced $\left(\mathrm{CD}^{+} \mathrm{CD}^{+} 5 \mathrm{RO}^{+}\right) \mathrm{CD}^{+} \mathrm{T}$ cells in human lung tissue that express $\mathrm{CD} 103^{+}$and $\mathrm{CD}^{+} 9^{+}$. Dots represent individual donors ( $n=10$ healthy lungs), and bars depict mean \pm SEM (1-way ANOVA, Tukey's multiple comparison). (E) The percentage of CD8 ${ }^{+}$Trm cells (CD8+CD45RO+ $\left.\mathrm{CD} 103^{+} \mathrm{CD}^{+} 9^{+}\right)$of the total antigen-experienced $\mathrm{CD} 8^{+} \mathrm{T}$ cell pool $\left(\mathrm{CD3}^{+} \mathrm{CD} 8^{+}\right.$ $\mathrm{CD} 5 \mathrm{RO}^{+}$) in the lungs of donors plotted against age (years). Dots represent individual donors. (F) The percentage of antigen-experienced (CD3 CD45RO+) CD8- $\mathrm{T}$ cells in human lung tissue that express $\mathrm{CD}^{-103^{+}}$and $\mathrm{CD}^{+} 9^{+}$. Dots represent individual donors ( $n=10$ healthy lung tissues), and bars depict mean \pm SEM (1-way ANOVA, Tukey's multiple comparison). (C) The proportion of antigen-experienced $\mathrm{CD} 8^{+} \mathrm{T}$ cells $\left(\mathrm{CD}^{+} \mathrm{CD} 45 \mathrm{RO} \mathrm{CD}^{+} \mathrm{CD}\right)$ isolated from the lung, blood, or spleen of donors that express CD103 and CD69. Bars represent individual donors. (H and I) Representative histograms

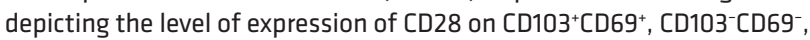
and $\mathrm{CD} \mathrm{C3}^{-\mathrm{CD} 69^{+}}$subsets of antigen-experienced CD8 ${ }^{+} \mathrm{T}$ cells $\left(\mathrm{CD}^{+}\right.$ $\left.\mathrm{CD} 8^{+} \mathrm{CD} 45 \mathrm{RO}^{+}\right)$isolated from the $(\mathbf{H})$ lung and (I) spleen of healthy donors. (J and $\mathbf{K}$ ) Graphs depict the mean fluorescence intensity (MFI) of CD28 on subsets of antigen-experienced CD8 ${ }^{+} T$ cells isolated from the (J) lung and (K) spleen. Symbols represent individual donors (1-way ANOVA, Tukey's multiple comparison). ${ }^{*} P<0.05 ;{ }^{* * *} P<0.0001$.

being poised for rapid responsiveness (11). Whether the human lung contains influenza-specific $\mathrm{CD}^{+}$Trm cells and whether these cells have a role in modulating the course of the disease is currently unknown.

In this study, using lung tissue from individuals who had consented to be organ donors, we analyzed the phenotype, functionality, and clonal composition of influenza virus-specific lung $\mathrm{CD}^{+}$Trm cells. We show that healthy human lung tissue contains a population of $\mathrm{CD}^{+}$Trm cells that are highly proliferative and whose progeny are polyfunctional. We observe an enrichment of influenza virus-specific $\mathrm{CD}^{+} \mathrm{T}$ cells within the Trm cell compartment and show that different specificities of influenza virusspecific $\mathrm{CD}^{+} \mathrm{T}$ cells differentiated into Trm cells with varying efficiencies. Ex vivo single-cell analysis of T cell receptor $\alpha \beta$ $(\mathrm{TCR} \alpha \beta)$ clonotypes within the influenza virus-specific lung CD ${ }^{+}$ Trm cell compartment provides clear evidence for the maintenance of TCR $\alpha \beta$ diversity within the long-lived CD8 ${ }^{+}$Trm cell pool with no indication of clonal skewing or TCR repertoire narrowing.

\section{Results}

A population of antigen-experienced $C D 8^{+} T$ cells expressing Trm cells markers is located in healthy human lung. We profiled intrapulmonary $\mathrm{T}$ cells within human lung tissue from organ donors between the ages of 22 and 68. Immunofluorescence analyses of tissue sections cut from human lung samples revealed an abundance of $\mathrm{CD}^{+} \mathrm{T}$ cells, some of which congregated into dense clusters (Figure 1A). To gain insight into the frequency of $\mathrm{CD}^{+} \mathrm{T}$ cells that could be resident within the lung tissue, we assessed these cells for the expression of CD69, a negative regulator of sphingosine-1 phosphate receptor 1 (S1P1R), and the integrin CD103, as expression of these markers distinguishes tissue resident memory $\mathrm{T}$ cells from circulating memory $\mathrm{T}$ cell subsets (12). The intrapulmonary memory $\mathrm{T}$ cell $\left(\mathrm{CD} 45 \mathrm{RO}^{+} \mathrm{CD}^{+}\right)$compartment could be divided into 3 subsets based on the expression of CD103 and CD69. The expression of the integrin CD103 on memory CD8 ${ }^{+} \mathrm{T}$ cells within human lung identifies cells with a Trm cell transcriptional profile (11); therefore, we define lung Trm cells as $\mathrm{CD} 103^{+} \mathrm{CD} 69^{+}$as Trm populations. In addition to the Trm cell population, the lung tissue also contained a CD103- ${ }^{-}$D $69^{+}$memory $\mathrm{T}$ cell subset and a population of memory $\mathrm{T}$ cells that lacked expression of both CD103 and CD69. These memory $T$ cell subsets are likely to be heterogeneous and comprise both circulating and tissue-bound cells (13).

The proportion of memory $\mathrm{CD}^{+} \mathrm{T}$ cells $\left(\mathrm{CD} 45 \mathrm{RO}^{+} \mathrm{CD}^{+}\right)$ recovered from healthy human lung tissue that were Trm cells (Figure $1, \mathrm{~B}-\mathrm{D})$ ranged from $20 \%-80 \%$ of the total memory $\mathrm{CD}^{+} \mathrm{T}$ cell pool, although on average, all 3 subsets (Trm, CD103-CD69 ${ }^{+}$, and $\left.\mathrm{CD} 103^{-} \mathrm{CD}^{-} 9^{-}\right)$were equally represented within the memory $\mathrm{CD}^{+}$ T cell compartment (Figure 1D). While there was no correlation between the proportion of memory $\mathrm{CD}^{+} \mathrm{T}$ cells expressing Trm cell markers in human lung and the age of the donors $(n=10)$, there was substantial variation between the individuals (Figure 1E). In contrast, $\mathrm{CD} 103^{+} \mathrm{CD} 69^{+}$Trm cells were rare in the memory CD $4^{+}$ T cell compartment (Figure 1, C and F). The majority (>60\%) of the lung memory $\mathrm{CD} 4^{+} \mathrm{T}$ cells $\left(\mathrm{CD} 45 \mathrm{RO}^{+} \mathrm{CD} 4^{+}\right)$were $\mathrm{CD} 103{ }^{-} \mathrm{CD} 69^{+}$ (Figure $1, \mathrm{C}$ and $\mathrm{F}$ ), and this was highly consistent across all donors tested. This expression pattern of CD69 and CD103 on human intrapulmonary memory $\mathrm{CD}^{+}$and $\mathrm{CD}^{+} \mathrm{T}$ cells closely resembles that observed on murine lung memory $\mathrm{T}$ cell subsets (14).

While Trm cells made up on average $40 \%$ of the intrapulmonary memory $\mathrm{CD}^{+} \mathrm{T}$ cell pool, this subset was undetectable when profiling memory $\mathrm{CD}^{+} \mathrm{T}$ cells in the blood (peripheral blood mononuclear cell [PBMC] samples from healthy nonmatched donors) and represented less than $10 \%$ of the total $\mathrm{CD} 8^{+}$memory $\mathrm{T}$ cell pool in human lymphoid tissue (spleen from nonmatched donors), indicating an enrichment of these cells within this mucosal tissue (Figure 1G). Prior studies have shown that Trm cells in mucosal tissue differed from those recovered from lymphoid compartments (15). In line with these studies, we found that lung CD8 ${ }^{+}$ Trm cells downregulated CD28 (Figure 1, H and J), which is indicative of TCR activation, while Trm cells isolated from the human spleen maintained expression of this costimulatory molecule (Figure 1, I and K). Collectively, these results show that human lung tissue contains a sizable pool of CD8 ${ }^{+}$Trm cells.

Functional profiles of memory $C D 8^{+} T$ cells in human lung tissue. To gain insight into the functional properties of intrapulmonary memory $\mathrm{CD}^{+} \mathrm{T}$ cells, we first measured the capacity of these cells to synthesize inflammatory cytokines after in vitro stimulation with PMA and ionomycin (ION). Profiling 7 organ donors revealed variable levels of IFN- $\gamma$ and TNF- $\alpha$ production across donors, ranging from $20 \%$ to $60 \%$ cytokine $^{+}$cells of the total $\mathrm{CD}^{+} \mathrm{C}-$ $\mathrm{D}_{45 \mathrm{RO}^{+}} \mathrm{T}$ cell pool (Figure 2, A and B). We observed no correlation between cytokine production and age (Supplemental Figure 1; supplemental material available online with this article; https:// doi.org/10.1172/JCI96957DS1).

We next assessed the functionality of the CD8 $8^{+}$Trm cell subset and compared it to that of the other memory $\mathrm{CD}^{+} \mathrm{T}$ cell sub-

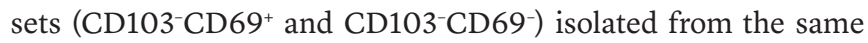
lung tissue (Figure 2C). The cytotoxic activity of Trm cells was assessed by measuring CD107a, granzyme B, and perforin pro- 
A

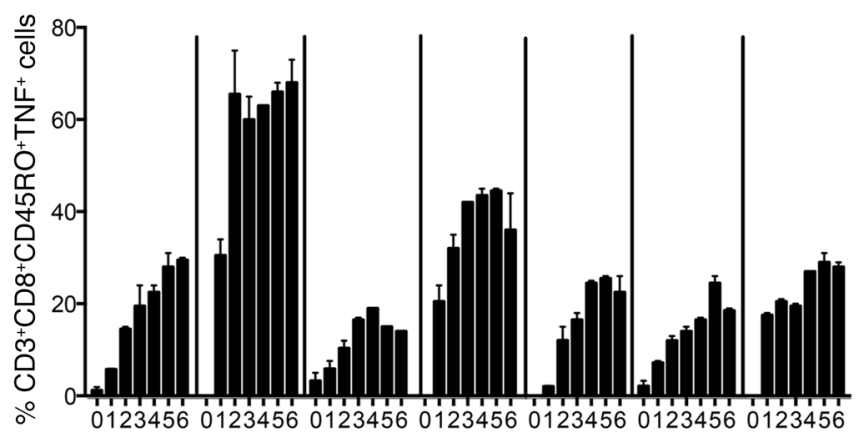

Hours after stimulation
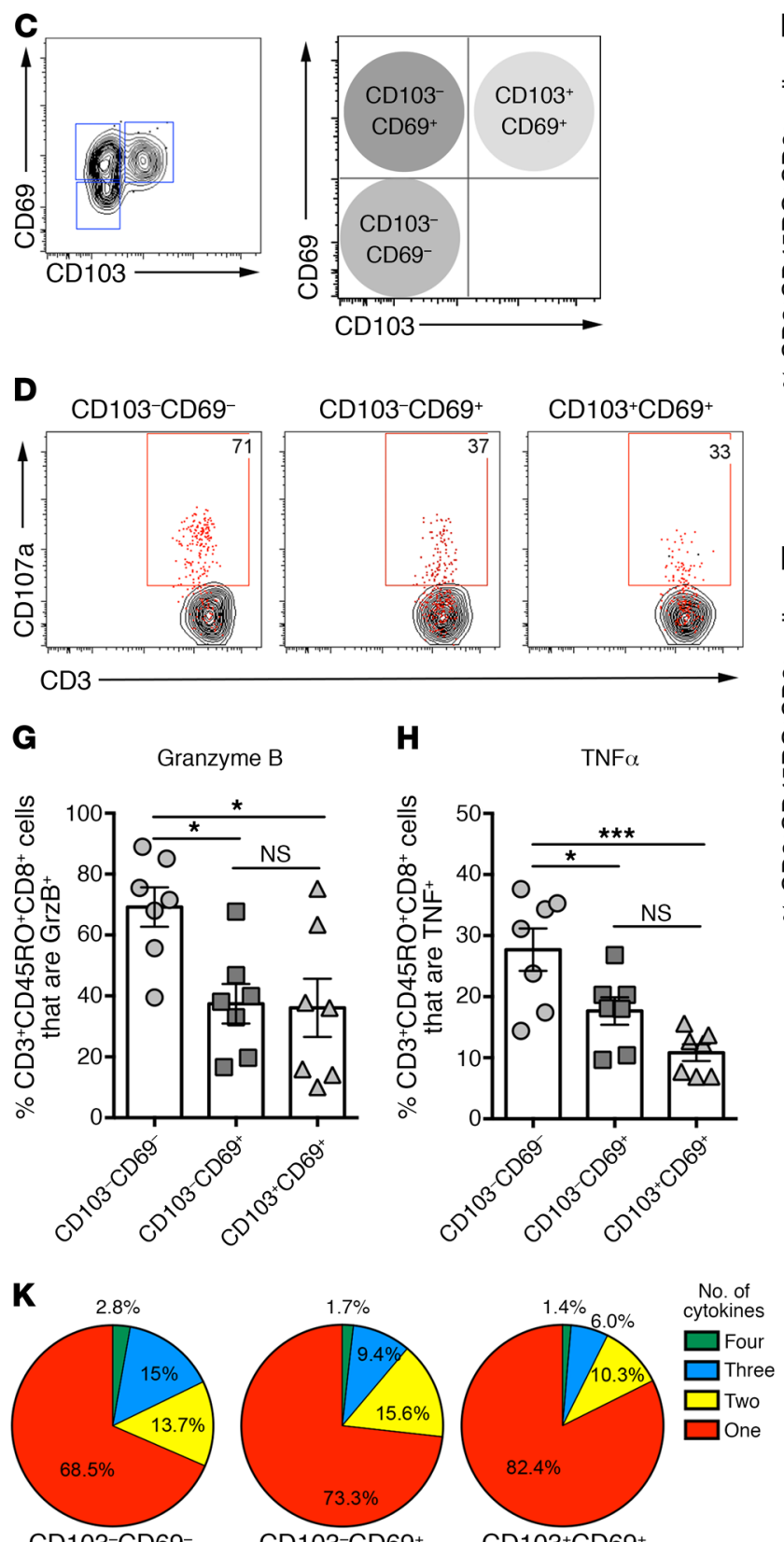

CD103-CD69-

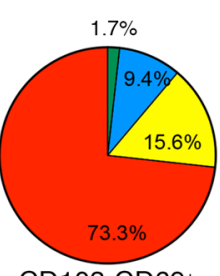

CD103-CD69+

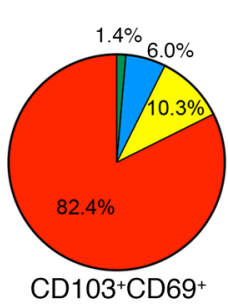

B

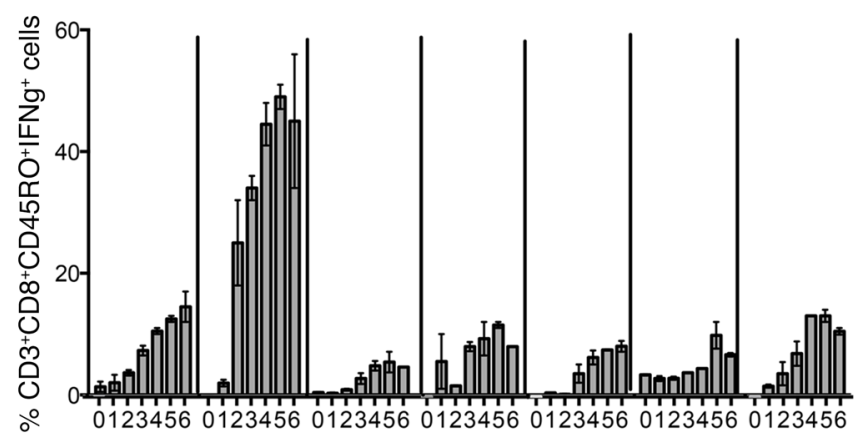

Hours after stimulation
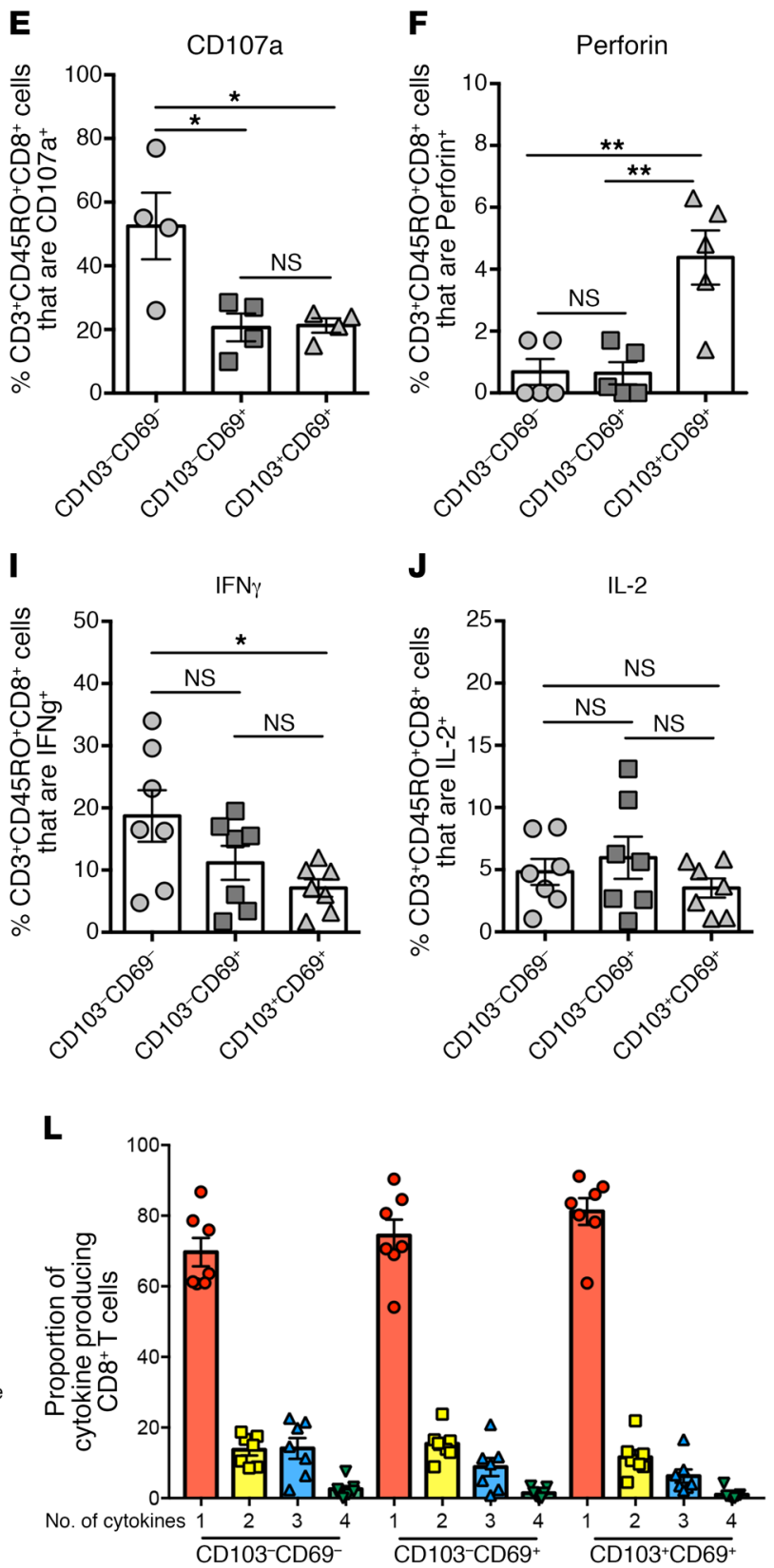
Figure 2. Functional profiles of memory $\mathrm{CD8}^{+} \mathrm{T}$ cells in human lung tissue. Proportion of antigen-experienced $C D 8^{+} T$ cells isolated from lung tissue expressing (A) TNF- $\alpha$ or (B) IFN- $\gamma$ at various time points after stimulation with PMA/ION. Seven donors are shown. (C) CD103 and CD69 expression by $C D 8^{+} C D 45 R 0^{+} T$ cells delineates 3 subsets: $C D 103^{+}{ }^{+} D 69^{+}$

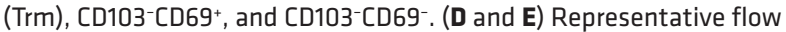
cytometry profiles showing the proportion of CD107a+ cells for each subset following 4 hours of stimulation with PMA/ION. Red dots indicate stimulated samples, while contour plots show unstimulated control cells. (E) Graph depicts data pooled from 4 donors; dots represent individual donors and bars represent mean \pm SEM ( $n=4$, 1-way ANOVA, Tukey's multiple comparison). (F-J) T cells isolated from human lung were stimulated for 5 hours with PMA/ION and the proportion of each $C D 8^{+} T$ cell subset (delineated as described in C) synthesizing (F) perforin, (C) granzyme B, (H) TNF- $\alpha$, (I) IFN- $\gamma$, and (J) IL-2 was assessed by intracellular cytokine staining. Dots represent individual donors, and bars represent mean \pm SEM ( $n=4-7,1$-way ANOVA, Tukey's multiple comparison). (K) Polyfunctional profiles of antigen-experienced $\mathrm{CD}^{+} \mathrm{T}$ cell subsets. Pie charts corre-

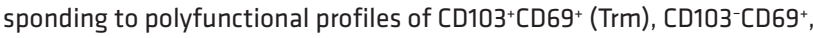
and CD103-CD69- $T$ cell subsets isolated from human lung tissue $(n=7)$ following 5 hours of stimulation with PMA/ION. Assessment of the mean proportion of cells making any combination of 1-4 cytokines (IFN- $\gamma$, TNF, IL-2, and granzyme B). (L) Dots depict individual donors, with bars representing mean + SEM. ${ }^{*} P<0.05 ;{ }^{* *} P<0.01 ;{ }^{* *} P<0.001$.

duction following a brief in vitro stimulation with PMA/ION. We found that while CD8 ${ }^{+}$Trm cells expressed lower levels of CD107a and granzyme $\mathrm{B}$ compared with the $\mathrm{CD} 103^{-} \mathrm{CD} 69^{-}$subset, Trm cells were more effective at producing perforin (Figure 2, D-G), which mirrors the expression pattern of these cytotoxic mediators within human liver $\mathrm{CD} 8^{+}$Trm cells (13). The CD103-CD69 memory $\mathrm{CD} 8^{+} \mathrm{T}$ cell subset was also more efficient at synthesizing TNF- $\alpha$ and IFN- $\gamma$ compared with the Trm cell subset (Figure $2, \mathrm{H}$ and I), while all memory $\mathrm{T}$ cell subsets profiled were comparable in their capacity to generate IL-2 (Figure 2J). The memory $\mathrm{CD}^{+} \mathrm{T}$ cell subsets exhibited a similar hierarchy of cytokine production when assessed for either mean fluorescent intensity of cytokine-producing cells or percentage of cytokine-producing cells (Supplemental Figure 2). The cytokine and phenotypic profile of the memory $\mathrm{CD} 8^{+} \mathrm{T}$ cell subset for each donor is presented in Supplemental Table 1. Assessment of the polyfunctionality of these memory $\mathrm{CD} 8^{+} \mathrm{T}$ cell subsets revealed that the vast majority of memory $\mathrm{CD} 8^{+} \mathrm{T}$ cells, irrespective of their expression pattern of CD103 and CD69, synthesized only 1 cytokine (Figure 2, K and L).

Expansion potential and functionality of lung memory $C D 8^{+} T$ cells. Subsets of human memory $\mathrm{CD} 8^{+} \mathrm{T}$ cells and $\mathrm{CD} 4^{+} \mathrm{T}$ cells were sort purified from the lung according to CD103 and CD69 expression, labeled with CFSE, and compared for their capacity to proliferate in response to anti-CD3 in the presence of exogenous IL-2. There was no difference in survival of the $\mathrm{CD} 8^{+} \mathrm{T}$ cell subsets in culture, with all 3 subsets showing equivalent levels of viability following overnight culture (Figure 3A). Assessment of cell division revealed that all memory $\mathrm{CD} 8^{+} \mathrm{T}$ cell subsets were capable of undergoing in vitro expansion with, on average, $60 \%-70 \%$ of cells within each subset undergoing at least 1 division after 10 days of culture (Figure 3, B and C). A comparison of the effector function of the divided cells following a brief restimulation revealed that, across all the subsets, $70 \%-85 \%$ of the divided cells could generate IFN- $\gamma$ and $80 \%-90 \%$ could synthesize TNF- $\alpha$, reflecting that the progeny of each of the memory $\mathrm{CD} 8^{+} \mathrm{T}$ cells subsets had supe- rior effector function compared with the parent population (Figure 2). Interestingly, an assessment of the polyfunctionality of the secondary effector cells for IFN- $\gamma$, TNF- $\alpha$, and granzyme B revealed that daughter cells derived from the Trm cell subset were more polyfunctional compared with the daughter cells derived from the $\mathrm{CD}^{203}{ }^{-} \mathrm{CD} 69^{+}$and the $\mathrm{CD} 103^{-} \mathrm{CD} 69^{-}$subsets (Figure 3, D and E).

Enrichment of influenza-specific $C D 8^{+} T$ cells in the lung Trm cell pool. We next assessed the abundance and functionality of influenza-specific memory $\mathrm{CD} 8^{+} \mathrm{T}$ cells in human lung tissue. The proportion of memory $\mathrm{CD}^{+} \mathrm{T}$ cells capable of responding to influenza virus infection was first measured using a coculture system in which we infected human lung tissue with influenza A virus in the presence of brefeldin $\mathrm{A}$ and assessed the cytokine production by memory $\mathrm{CD} 8^{+} \mathrm{T}$ cell subsets 18 hours later (7). After 18 hours in culture, approximately $7 \%$ of the lung cells of varying phenotypes were infected with influenza virus (Figure 4A), as assessed by intracellular staining for the viral nuclear protein (NP). The majority (50\%) of memory $\mathrm{CD}^{+} \mathrm{T}$ cells synthesizing antiviral cytokines in response to ex vivo influenza virus infection were within the Trm cell subset (Figure 4, B and C), highlighting the potent capacity of this memory subset to rapidly generate effector cytokines in response to influenza virus infection within human lung tissue. This is consistent with recent reports that human lung tissue resident memory cells constitutively express deployment-ready mRNAs encoding effector molecules, which is reflective of these cells being poised for rapid responsiveness (11).

To further characterize the influenza-specific memory $\mathrm{CD} 8^{+} \mathrm{T}$ cells within human lung, we used a panel of HLApeptide tetrameric complexes and enumerated the influenza virus-specific cells by flow cytometry (5). Within our cohort, we identified 9 donors with HLA types for which HLA tetramers loaded with influenza A immunodominant epitopes were available. These included donors who were HLA-B57 $(n=3)$, HLA-A3 $(n=3)$, and HLA-A2 $(n=4)$. The proportion of influenzaspecific (tetramer positive) $\mathrm{CD} 8^{+} \mathrm{T}$ cells in the total memory $\mathrm{CD}^{+} \mathrm{T}$ cell pool across the donors ranged from $0.3 \%$ to $8.0 \%$. While we observed no correlation between the size of the influenza-specific memory $\mathrm{CD} 8^{+} \mathrm{T}$ cell pool and the age of the donors (Figure 4D), a comparison of the proportion of influenza virus-specific memory $\mathrm{CD} 8^{+} \mathrm{T}$ cells across the different HLA types revealed that HLA-B57 individuals had, on average, a higher proportion of influenza-specific cells (Figure 4E). As the persistence of memory $\mathrm{CD} 8^{+} \mathrm{T}$ cells within the lung is associated with the development of Trm cells, we next assessed whether the larger proportion of influenza-specific $\mathrm{CD}^{+} \mathrm{T}$ cells in the HLA-B57 individuals was associated with a higher conversion efficiency of influenza-specific HLA-B57-NP ${ }_{199-207}^{+}$ $\mathrm{CD} 8^{+} \mathrm{T}$ cells into Trm cells. To assess this, we gated on HLAA2-M1 $1_{58-66}$, HLA-A3-NP $265-273$, and HLA-B57-NP ${ }_{199-207}$ tetramerbinding cells and checked these cells for the expression of the Trm cell markers CD103 and CD69 (Figure 4, F-I). Strikingly, this analysis revealed that, on average, $80 \%$ of $\mathrm{NP}_{199-207}{ }^{-}$ specific $\mathrm{CD} 8^{+} \mathrm{T}$ cells in the HLA-B57 donors had differentiated into Trm cells, while only $25 \%$ of $\mathrm{M}_{58-66}$-specific $\mathrm{CD} 8^{+} \mathrm{T}$ cells in the HLA-A2 donors adopted a Trm cell phenotype. In addition, we found that approximately $50 \%$ of the $\mathrm{NP}_{265-273}-$ specific $\mathrm{CD} 8^{+} \mathrm{T}$ cells in the HLA-A3 donors differentiated into 
Table 1. Frequencies of shared CDR3 $\alpha$-CDR3 $\beta$ signatures present in 2 or more memory CD8 ${ }^{+}$T cell subsets are shown.

\begin{tabular}{|c|c|c|c|c|c|c|c|c|c|c|}
\hline Lung donor & Clonotype ID & $\operatorname{CDR3} \beta$ & TRBV & TRBJ & $\operatorname{CDR3} \alpha$ & TRAV & TRAJ & $\begin{array}{l}\mathrm{CD69}^{+} \\
\mathrm{CD}^{-} 3^{+}\end{array}$ & $\begin{array}{l}\mathrm{CD69}^{+} \\
\mathrm{CD} 103^{-}\end{array}$ & $\begin{array}{l}\mathrm{CD69}^{-} \\
\mathrm{CD}^{-} 3^{-}\end{array}$ \\
\hline \multirow{2}{*}{$\begin{array}{l}\text { Donor C } \\
\text { HLA-A2 } \\
\text { M1(58-66) }\end{array}$} & AJ & ND & & & CAGGGSQGNLIF & TRAV27 & TRAJ42 & & $3.1 \%$ & $3.1 \%$ \\
\hline & $Y(i)$ & CASSSRSHQPQHF & TRBV19 & TRB|1-5 & CAGSYGGSQGNLIF & TRAV25 & TRA|42 & $50.0 \%$ & $12.5 \%$ & $9.4 \%$ \\
\hline \multirow{3}{*}{$\begin{array}{l}\text { Donor D } \\
\text { HLA-B57 } \\
\text { NP(199-207) }\end{array}$} & $A$ & CATSPGSVLETQYF & TRBV24-1 & TRB|2-5 & CAVKGETSGSRLTF & TRAV41 & TRA|58 & $23.33 \%$ & $13.64 \%$ & $3.57 \%$ \\
\hline & B & ND & & & CAVKGETSGSRLTF & TRAV41 & TRA|58 & $3.33 \%$ & & $3.57 \%$ \\
\hline & $\mathrm{AP}$ & ND & & & CIV\#\#NYGQNFVF & TRAV26-1 & TRA|26 & $10.00 \%$ & $27.27 \%$ & \\
\hline \multirow{7}{*}{$\begin{array}{l}\text { Donor B } \\
\text { HLA-A3 } \\
\text { NP(265-273) }\end{array}$} & $A(i)$ & CASSWDVSNQPQHF & TRBV5-5 & TRB|1-5 & CAGVTTSGFRLTF & TRAV25 & TRA|58 & $31.25 \%$ & $9.09 \%$ & $31.25 \%$ \\
\hline & $A(i i)$ & CASSWDVSNQPQHF & TRBV5-5 & TRB|1-5 & ND & & & $3.13 \%$ & $3.03 \%$ & $12.50 \%$ \\
\hline & A(iii) & ND & & & CAGVTTSGSRLTF & TRAV25 & TRA|58 & $9.38 \%$ & $3.03 \%$ & \\
\hline & {[} & CASSQWTSGRGETQYF & TRBV14 & TRB|2-5 & CAIRAGGYNKLIF & TRAV14/DV4 & TRA|4 & $12.50 \%$ & $21.21 \%$ & $9.38 \%$ \\
\hline & D & ND & TRBV14 & & CAIRAGGYNKLIF & TRAV14/DV4 & TRAJ4 & & $3.03 \%$ & $3.13 \%$ \\
\hline & $U(i)$ & CSVLGLETQYF & TRBV29-1 & TRB|2-5 & CAGLRSNDYKLSF & TRAV25 & TRA|20 & & $3.03 \%$ & $3.13 \%$ \\
\hline & U(ii) & CSVLGLETQYF & TRBV29-1 & TRB|2-5 & ND & & & & $3.03 \%$ & $3.13 \%$ \\
\hline
\end{tabular}

Trm cells. Thus, the size of the influenza-specific $\mathrm{CD}^{+} \mathrm{T}$ cell population persisting within the lung correlated with the efficiency with which the cells differentiated into Trm cells (Figure 4J).

Maintenance of TCR $\alpha \beta$ repertoire diversity within the human lung CD8 ${ }^{+}$Trm cell subset. To understand how the lung CD8 ${ }^{+}$Trm cell population relates to the lung $\mathrm{CD} 103^{-} \mathrm{CD}^{-} 9^{+}$or $\mathrm{CD} 103^{-} \mathrm{CD} 69^{-} \mathrm{CD} 8^{+}$ $\mathrm{T}$ cell subsets, both in terms of clonal origin and clonal diversity, we analyzed the TCR $\alpha \beta$ repertoire within $\mathrm{CD} 103^{+} \mathrm{CD} 69^{+}, \mathrm{CD} 103$ $\mathrm{CD}^{+} 9^{+}$, and $\mathrm{CD} 103^{-}{ }^{-}{ }^{-6} 9^{-} \mathrm{CD}^{+} \mathrm{T}$ cell subsets across 3 different immunodominant $\mathrm{T}$ cell specificities, HLA-A2-M1 ${ }_{58-66}$, HLA-A3$\mathrm{NP}_{265-273}$, and HLA-B57-NP ${ }_{199-207}(5,16)$. As predicted, CD8 ${ }^{+} \mathrm{T}$ cells directed at distinct epitopes displayed different biases in TCR- $\beta$ variable (TRBV) and TCR- $\alpha$ variable (TRAV) usage as well as different lengths of complementarity-determining region $3 \alpha(C D R 3 \alpha)$ and CDR3 $\beta$ loops (Figure 5). Prominent TRBV chain usage was TRBV19 (for HLA-A2-M1 $1_{58-66}$ ), TRBV 14 and TRBV5.5 (for HLA-A3-NP ${ }_{265-273}$ ), and TRBV24-1 and TRBV19 (for HLA-B57-NP ${ }_{199-207}$ ), while the dominant TRAV chain usage was TRAV27 and TRAV25 (for HLAA2-M1 ${ }_{58-66}$ ), TRAV14/DV4 and TRAV25 (for HLA-A3-NP ${ }_{265-273}$ ), and TRAV41 and TRAV 26-1 (for HLA-B57-NP ${ }_{199-207}$ ) (Table 1). TCR $\alpha \beta$ clonotypes also varied in the predominant length of the CDR3 loops, with $\mathrm{CD}^{+} \mathrm{T}$ cells directed at HLA-A2-M1 ${ }_{58-66}$ utilizing CDR3 $\beta$ of 8 aa and CDR3 $\alpha$ of 9 aa, HLA-A3-NP ${ }_{265-273}$ with CDR3 $\beta$ of 9 aa and CDR3 $\alpha$ of 9 aa, and HLA-B57-NP ${ }_{199-207}$ with CDR3 $\beta$ of 11 aa and CDR $3 \alpha$ of 8 aa (Figure $5 \mathrm{~A}$ ). The diversity of the TCR $\alpha \beta$ repertoire was comparable across 3 epitopes, with 44, 44, and 31 individual clonotypes detected across 96, 80, and 97 sequences for HLAA2-M1 ${ }_{58-66}$, HLA-B57-NP ${ }_{199-207}$ and HLA-A3-NP ${ }_{265-273}$, respectively (Supplemental Table 2).

Further analysis of individual paired CDR $3 \alpha-C D R 3 \beta$ signatures across the lung $\mathrm{CD} 103^{+} \mathrm{CD} 69^{+}$Trm cells or CD103-CD69+

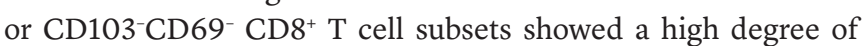

TCR $\alpha \beta$ clonotype sharing between the 3 lung memory subsets (Figure 5B). TCR $\alpha \beta$ signatures found in Trm cells were shared with $\mathrm{CD} 103^{-} \mathrm{CD} 69^{+}$and $\mathrm{CD}^{-}{ }^{-} \mathrm{CD}^{-} 9^{-}$populations at $62.5 \%$ and 75\% (HLA-A2-M1 ${ }_{58-66}$ ), 36.7\% and 26.7\% (HLA-B57-NP ${ }_{199-207}$ ), and $75.0 \%$ and $56.3 \%$ (HLA-A3-NP $265-273$ ), respectively. This mainly reflected sharing of the high-frequency prominent TCR $\alpha \beta$ clonotypes (Figure $5 \mathrm{C}$ ), suggesting that the main TCR $\alpha \beta$ signatures within Trm cells and $\mathrm{CD} 103^{-} \mathrm{CD}^{-} 9^{+}$and $\mathrm{CD} 103^{-} \mathrm{CD} 69^{-}$populations arose from a common precursor rather than originating from separate lineages. However, despite such a high degree of sharing and the presence of common TCR $\alpha \beta$ clonotypes across distinct memory $\mathrm{CD}^{+} \mathrm{T}$ cell populations in human lung, the clonal size of some clonotypes differed across memory subsets (Table 1 and Figure 6). This could possibly reflect the timing and/ or strength of the antigenic encounter, which in turn could influence the acquisition of CD69 and CD103 molecules. Clonal diversity within the 3 populations was also comparable as per analysis of Simpson's diversity indexes $(P=0.307$; 1-way ANOVA; Figure $5 \mathrm{C}$ ), suggesting no loss of TCR $\alpha \beta$ diversity in any of the lung influenza-specific memory populations.

Overall, our data clearly demonstrate that human lung CD8 ${ }^{+}$ Trm cells draw from the same repertoire as $\mathrm{CD} 103^{-} \mathrm{CD} 69^{+}$and $\mathrm{CD}^{103}{ }^{-} \mathrm{CD} 69^{-}$populations, with little evidence for TCR $\alpha \beta$ clonotypes skewing. Thus, clonal TCR $\alpha \beta$ diversity is maintained within the human lung Trm cell compartment.

\section{Discussion}

Here we analyzed the phenotype, functionality, and clonal composition of influenza virus-specific lung-resident memory CD8 ${ }^{+}$ Trm cells. We show that human lung tissue contains a population of $\mathrm{CD}^{+}$Trm cells that are highly proliferative and whose progeny are polyfunctional. We observe an enrichment of influenza virus- 
A
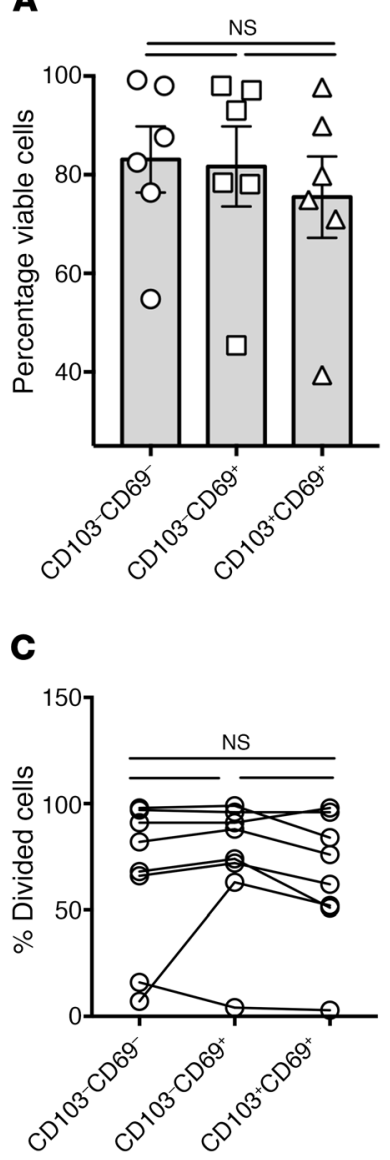

D
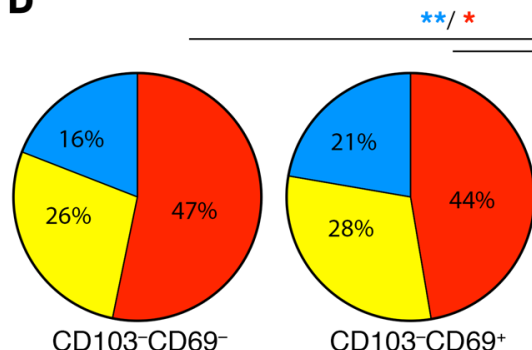

Number of cytokines

$\square$ One $\square$ Two $\square$ Three

B

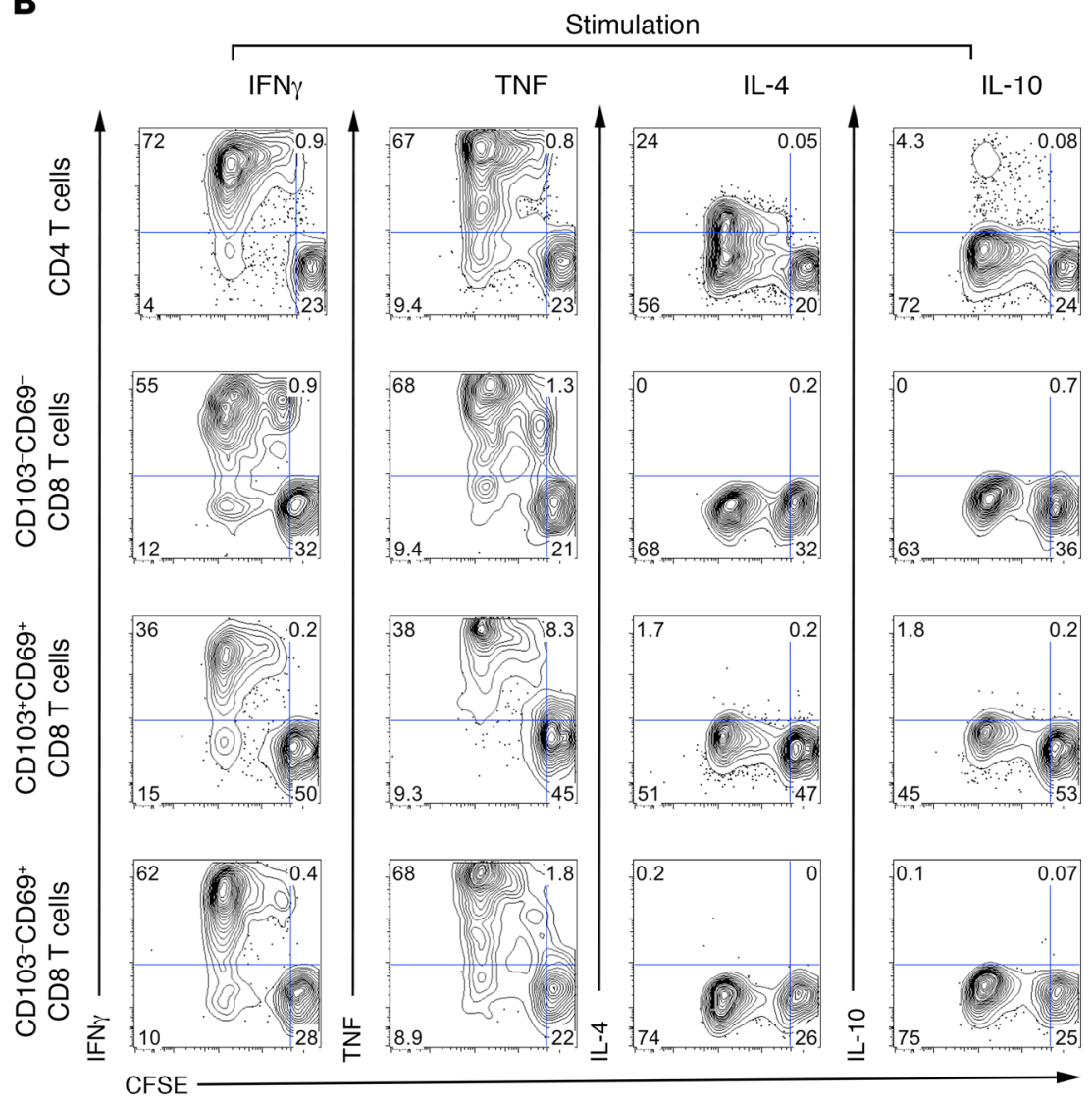

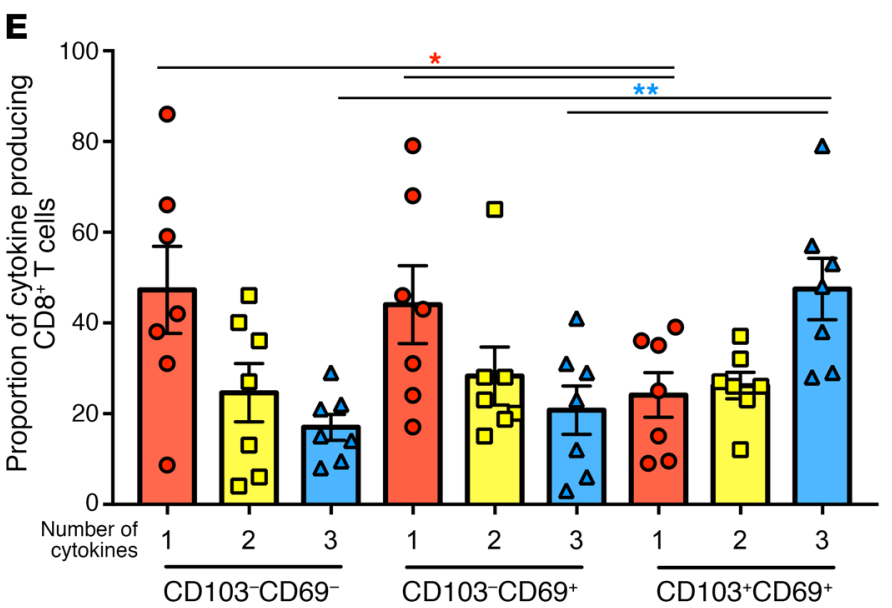

Figure 3. Lung Trm cells are highly proliferative and produce polyfunctional secondary effector cells. Memory CD $8^{+} \mathrm{T}$ cell subsets, delineated based on the expression of $\mathrm{CD103}$ and $\mathrm{CD69}$, were sort purified from human lung tissue and cultured overnight. (A) The graph depicts the proportion of viable cells within each subset ( $n=6$ donors, 2-way ANOVA, Tukey's multiple comparison). Memory CD4+ and CD8 ${ }^{+}$T cell subsets, delineated based on the expression of CD103 and CD69, were purified from human lung tissue. (B) Representative flow cytometry plots show the dilution of CFSE dye following stimulation for 10 days with anti-CD3 and cytokine production following 5 hours restimulation with PMA/ION. (C) Graph shows the proportion of divided cells for each of the $C D 8^{+} T$ cell subsets; line connects samples from individual donors ( $n=8$ donors, 1 -way ANOVA, Tukey's multiple comparison). (D and $\left.\mathbf{E}\right)$ Polyfunctional

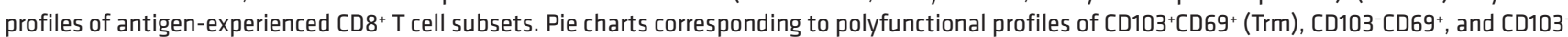
CD69- $T$ cell subsets isolated from human lung tissue, cultured for 10 days, and then stimulated for 5 hours with PMA/ION. Assessment of the mean proportion of $\mathrm{CD}^{+} \mathrm{T}$ cells making any combination of 1-3 cytokines $\pm \mathrm{SEM}$ (IFN- $\gamma$, TNF, and granzyme B). (E) Graph depicts values for individual donors ( $n=7$ donors, 2-way ANOVA, Šidák's multiple comparison). ${ }^{*} P<0.05$; ${ }^{* *} P<0.01$. 
A

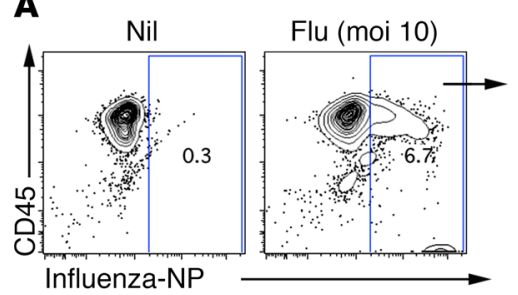

B $\mathrm{CD} 103^{-} \mathrm{CD} 69^{-}$
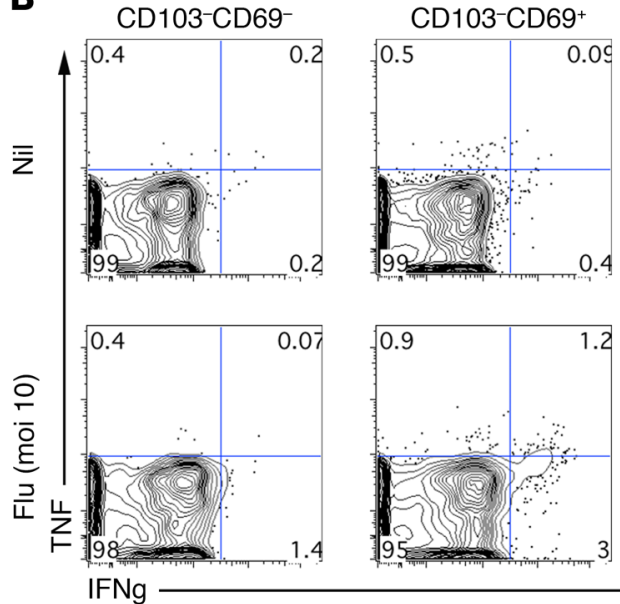
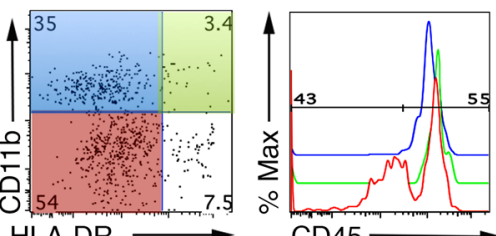

C

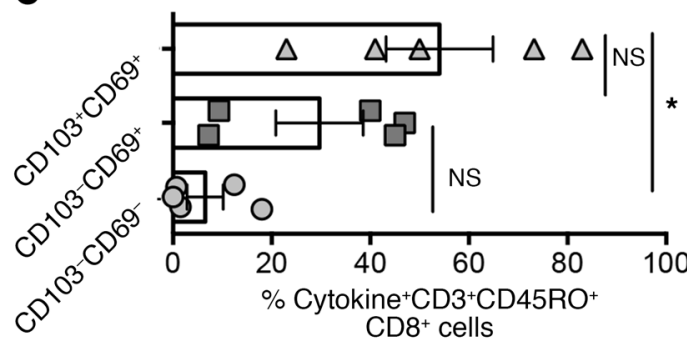

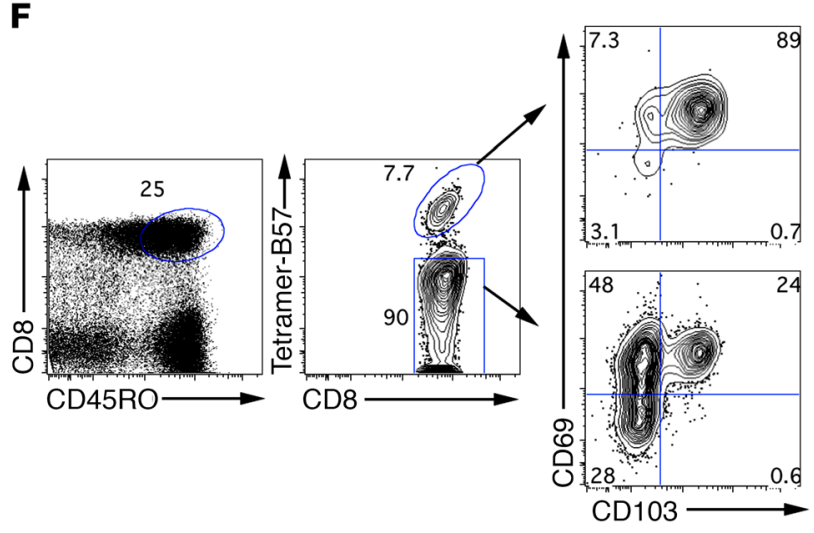

H

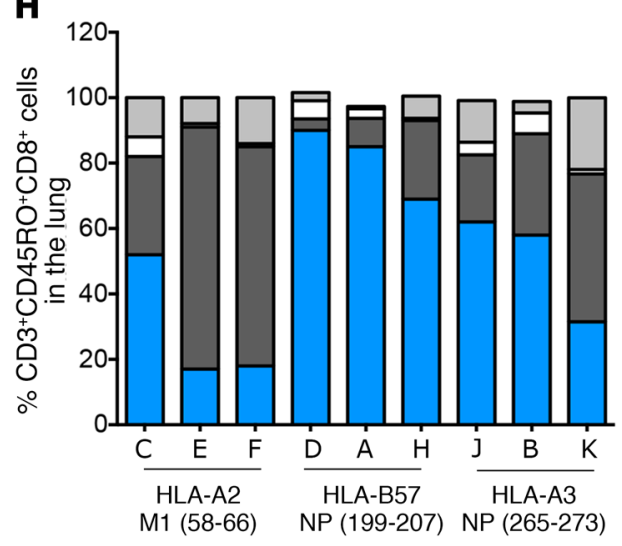

$\square^{\mathrm{CD} 103-\mathrm{CD}^{-} 9^{+}}$
I

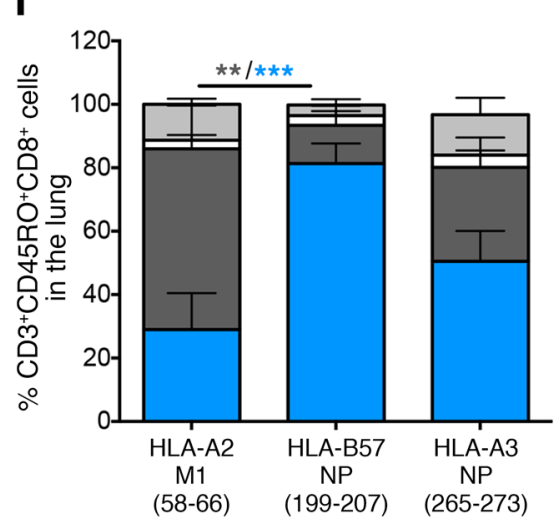

CD103-CD69+ $\mathrm{CD}^{103}{ }^{+} \mathrm{CD} 69^{+}$
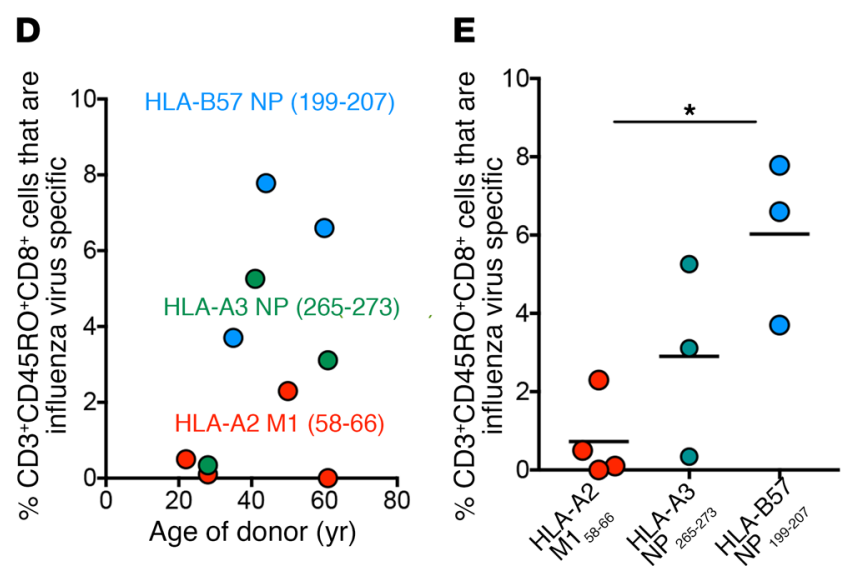

G

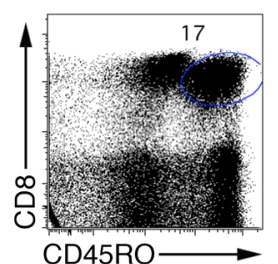

CD45RO

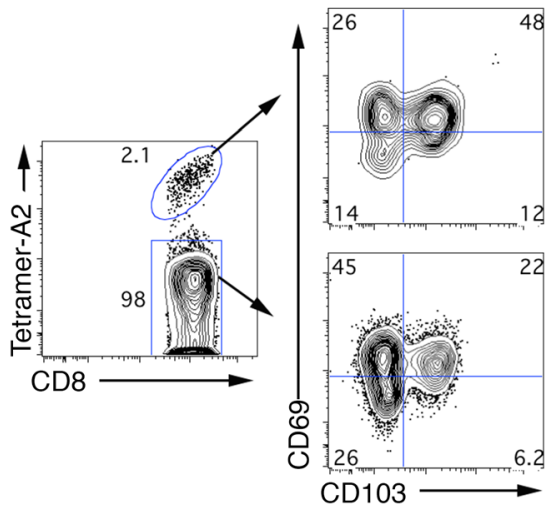

J

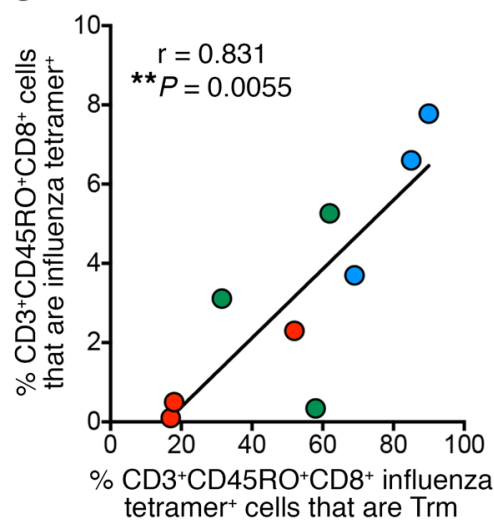

tetramer ${ }^{+}$cells that are Trm 
Figure 4. Enrichment of influenza-specific CD8 ${ }^{+} T$ cells in the lung Trm cell pool. (A) Whole lung tissue was infected with influenza virus (PR8) at $\mathrm{MOI}$ of 10 and the proportion and identity of infected cells was measured 18 hours later by intracellular staining for influenza virus NP. (B and C) Proportion of each memory CD8 ${ }^{+} T$ cell subset (delineated based on the expression of CD103 and CD69) producing cytokines (IFN- $\gamma$ and TNF- $\alpha$ ) following 18 hours of stimulation with influenza virus. (B) Representative flow cytometry profile staining for TNF- $\alpha$ and IFN- $\gamma$ on antigen-experienced $\mathrm{CD}^{+} \mathrm{T}$ cell subsets with (Flu moi 10 ) or without (Nil) virus stimulation. (C) Data shown are the mean \pm SEM ( $n=5$ donors, 1-way ANOVA, Tukey's multiple comparison). (D) The percentages of influenza tetramer ${ }^{+} C D 8^{+}$of the total antigen-experienced $\mathrm{CD}^{+} \mathrm{T}$ cell pool $\left(\mathrm{CD3}^{+} \mathrm{CD} 8^{+} \mathrm{CD} 45 \mathrm{RO} \mathrm{O}^{+}\right)$in the lungs of donors plotted against age (years). (E) The percentage of influenza tetramer ${ }^{+} C D 8^{+} T$ cells of the total antigen-experienced $C D 8^{+} T$ cell pool $\left(\mathrm{CD3}^{+} \mathrm{CD}^{+} \mathrm{CD} 45 \mathrm{RO}^{+}\right)$in the lungs of donors plotted against HLA type ( $n=3-4$ donors, 1-way ANOVA, Tukey's multiple comparison). ( $\mathbf{F}$ and $\mathbf{G})$ Representative flow cytometry staining assessing the expression of CD103 and CD69 on (F) HLA-B57-NP ${ }_{199}$ specific or (C) HLA-A2-M1 ${ }_{58}$-specific CD8 ${ }^{+} \mathrm{T}$ cells isolated from lung tissue. (H) The proportion of influenza virusspecific $\mathrm{CD}^{+}{ }^{+} \mathrm{T}$ cells $\left(\mathrm{CD}^{+}{ }^{+} \mathrm{CD} 45 \mathrm{RO}{ }^{+} \mathrm{CD} 8{ }^{+}\right.$tetramer $\left.{ }^{+}\right)$isolated from the lung of donors that express $\mathrm{CD} 103$ and $\mathrm{CD} 69$. Bars represent individual donors. (I) Data pooled for all donors (A2, $n=3$; B57, $n=3 ; A 3, n=3$ ). Shown is the mean \pm SEM (2-way ANOVA, Šidák's multiple comparison). (J) Graph depicts the Pearson's correlation between the proportion of tetramer-binding cells of the total $\mathrm{CD}^{+}{ }^{+} \mathrm{CD} 8{ }^{+} \mathrm{CD} 45 \mathrm{RO}^{+}$pool relative to the proportion of Trm cells $\left(\mathrm{CD} 103^{+} \mathrm{CD}^{+} 9^{+}\right)$among the tetramer ${ }^{+}$cells. Dots represent individual donors. ${ }^{*} P<0.05$; ${ }^{*} P<0.01 ;{ }^{* *} P<0.001$.

specific $\mathrm{CD} 8^{+} \mathrm{T}$ cells within the Trm cell compartment and show that different specificities of influenza virus-specific $\mathrm{CD} 8^{+} \mathrm{T}$ cell differentiated into Trm cells with varying degrees of efficiency. Ex vivo single-cell analysis of TCR $\alpha \beta$ clonotypes within the influenza virus-specific lung $\mathrm{CD} 8^{+} \mathrm{Trm}$ cell compartment provides clear evidence for the maintenance of TCR $\alpha \beta$ diversity within the longlived $\mathrm{CD} 8^{+} \mathrm{Trm}$ cell pool, with no indication of clonal skewing or TCR repertoire narrowing.

The assessment of the effector function of the progeny of Trm cells has been difficult to measure using mouse models. This is because murine Trm cells are difficult to expand ex vivo and are highly susceptible to apoptosis following tissue dissociation (17). This has recently been attributed to these cells expressing elevated levels of ARTC2, a cell-surface ADP-ribosyltransferase that mediates $\mathrm{NAD}^{+}$-induced cell death (NICD) through the ribosylation of the ion channel P2X7 (18). Here, we show that Trm cells isolated from human lung tissue can survive in culture and can undergo robust ex vivo proliferation. Furthermore, the daughter cells of this subset have enhanced effector function compared with the parent cell population. This work highlights that Trm cells are not only capable of immediate effector function, but in addition, can proliferate in response to restimulation, producing polyfunctional secondary effector cells, thereby fueling a sustained local immune response.

Using an influenza virus mouse model, we have recently shown that different specificities of influenza-specific $\mathrm{CD} 8^{+} \mathrm{T}$ cells were recruited into the lung Trm cell pool with varying efficiencies (19). As Trm cell development within the lung is heavily influenced by local antigen recognition $(9,20)$, the relative epitope abundance within the lung over the course of an influenza virus infection likely modulates the immunodominance hierarchy within the Trm cell compartment, the relative epitope abundance within the lung over the course of an influenza virus infection likely modulates the immunodominance hierarchy within the Trm cell compartment $(19,21)$. The varying efficiencies with which $C D 8^{+} \mathrm{T}$ cells specific for the viral NP and M1 differentiated into Trm cells $(80 \%$ and $25 \%$, respectively) could be driven by differences in the abundance of the viral M1 and NP epitopes within the lung tissue during influenza virus infection.

As local cognate antigen recognition within the tissue is a major factor shaping the size and repertoire of the Trm cell pool, it is plausible that the HLA type of individuals could affect their capacity to develop Trm cells. The high proportion of influenzaspecific Trm cells in HLA-B57 individuals could reflect a difference among HLA-A- and HLA-B-restricted epitopes in developing into Trm cells or could possibly reflect an enhanced capacity of HLA-B57 individuals to form Trm cells. It is noteworthy that the HLA-B57 allele is highly associated with drug-induced inflammatory disease of the skin and with the development of psoriasis; both of these conditions have been recently linked to skin-resident memory $\mathrm{T}$ cells (22-24). Further studies and a larger cohort of clinical samples are required before such an association between HLA type and Trm cell development can be made.

It is well established that TCR $\alpha \beta$ repertoire diversity within antigen-specific $\mathrm{T}$ cells has major consequences for subsequent immune responses in both animal models and human disease. A diverse TCR $\alpha \beta$ repertoire provides a greater range of TCR clonotypes with scope for the preferential selection of high-avidity TCRs into the immune response $(25,26)$. This is a particular advantage for viral control, as diverse TCR repertoires with high pMHC avidity TCR clonotypes are potentially capable of recognizing newly emerging viral escape variants $(27,28)$. Thus, preservation of TCR $\alpha \beta$ clonal diversity within influenza-specific Trm cells in human lungs has important implications for effective control of viral infections, including influenza viruses.

Furthermore, such a high degree of clonal sharing, especially among the prevalent clones, between Trm cells and $\mathrm{CD}_{103^{-}}$ $\mathrm{CD} 9^{+}$and $\mathrm{CD}^{-103}{ }^{-} \mathrm{CD} 69^{-}$populations suggests common clonal precursors across all 3 lung memory populations. Our previous studies showed a higher degree of TCR diversity within the central memory $(\mathrm{Tcm})$ versus Tem populations and suggested that Tem are derived from Tcm populations, with Tcm subsets maintaining clonal diversity (29). Here, we provide the first evidence, to our knowledge, for the paired TCR $\alpha \beta$ clonal selection within human tissue Trm cell pools across 3 different influenza-specific $\mathrm{CD}^{+} \mathrm{T}$ cell specificities, HLA-A2-M1 ${ }_{58-66}$, HLA-A3-NP ${ }_{265-273}$, and HLA-B57- $\mathrm{NP}_{199-20 \%}$ Our study clearly shows that the human lung Trm cell population retains its clonal diversity for subsequent influenza encounters rather than being skewed toward a limited number of selected TCR $\alpha \beta$ clones. A recent study (30) provided a dissection of a single TCR chain (TCR $\beta$ ) within antigenspecific Trm cells in the skin by deep sequencing and found that, for every abundant Trm cell clone generated in the skin, an abundant Tcm cell clone bearing the identical TCR was present in the lymph node, which is indicative of antigen-reactive skin $\mathrm{Trm}$ and $\mathrm{Tcm}$ cell clones being derived from a common naive $\mathrm{T}$ cell precursor. As matched blood samples from our lung donors were unavailable, we could not compare the clonal composition and diversity of lung Trm cell populations to Tcm or Tem sets from peripheral blood. 
A

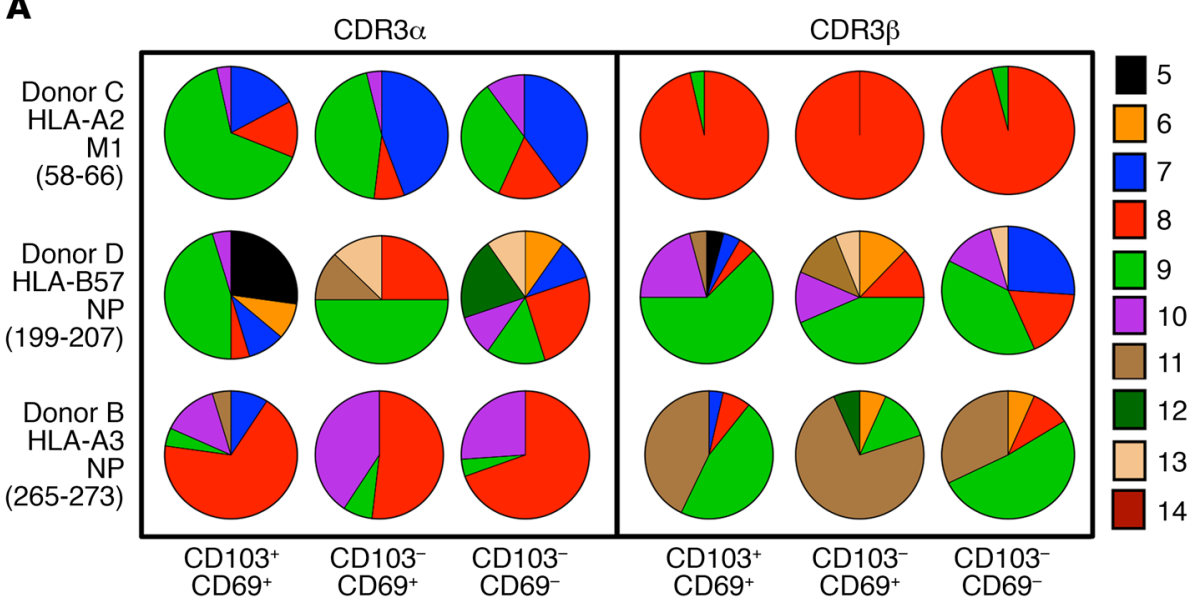

Figure 5. Common TCR $\alpha \beta$ repertoire within lung Trm cells and CD103-CD69 ${ }^{+}$and CD103-CD69- subsets. Influenza virus-specific CD8+ T cells (CD3+CD45RO+CD8+tetramer') isolated from the lung of healthy donors were single-cell sorted based on the expression of CD103 and CD69 into Trm (CD103+CD69+), CD103-CD69+, and CD103-CD69- populations. TCR $\beta$ analysis across 3 prominent influenzaspecific epitopes (HLA-A2-M1 ${ }_{58-66}$, HLA-A3$\mathrm{NP}_{265-273}$, or HLA-B57-NP ${ }_{199-207}$ ) were analyzed according to their (A) CDR3 $\alpha$ and CDR3 $\beta$ length; (B) frequency of TCR $\alpha \beta$ clonotype sharing between Trm and either CD103-CD69+ or CD103-CD69- populations; and (C) Simpson's diversity index.

\section{B}

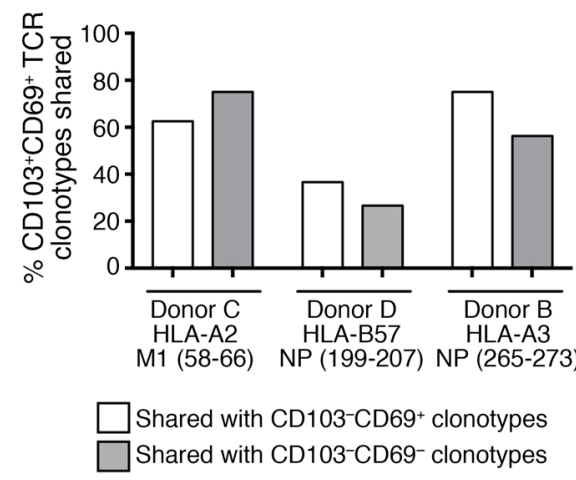

C

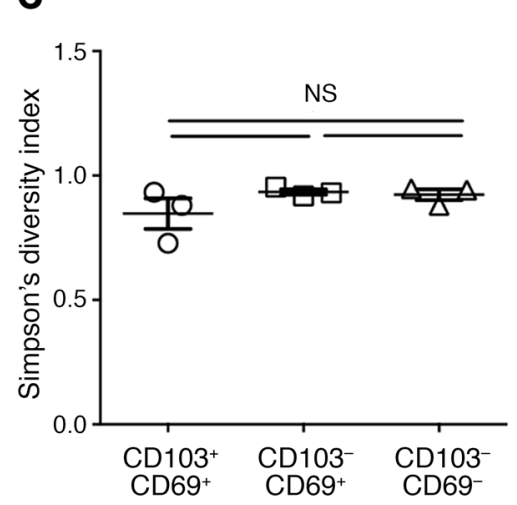

As exemplified by our previous studies, our single-cell ex vivo TCR analyses are sensitive to detecting TCR skewing within epitope-specific $\mathrm{CD} 8^{+} \mathrm{T}$ cell subsets in mice and humans. In mice, skewed and restricted TCR usage was previously found within Tem subsets across 2 distinct influenza-specific $\mathrm{CD}^{+} \mathrm{T}$ cell populations (31). Similarly, we found a selection of specific TCRs in highavidity subsets within influenza-specific $\mathrm{CD} 8^{+} \mathrm{T}$ cell responses $(32,33)$. In humans, we have detected TCR skewing in the context of solid organ transplant recipients during acute EBV and CMV reactivation events (34).

Overall, our direct ex vivo assessment of paired TCR $\alpha \beta$ repertoires revealed a high degree of clonal sharing across influenzaspecific Trm cells and CD103-CD69+ and CD103-CD69- memory populations, all retaining diverse TCR $\alpha \beta$ profiles. This has important implications for effective $\mathrm{CD} 8^{+} \mathrm{T}$ cell function and protection against the generation of viral escape mutants.

In summary, we show that human lung tissue harbors a large population of $\mathrm{CD} 8^{+}$Trm cells that are highly proliferative, polyfunctional, and composed of a diverse TCR $\alpha \beta$ repertoire. We show a direct correlation between the size of the influenzaspecific $\mathrm{CD}^{+} \mathrm{T}$ cell population persisting within the lung and the efficiency in which these cells differentiate into Trm cells. Hence, greater understanding of the drivers of lung Trm cell development will permit optimization of their lodgement and, in turn, result in enhanced retention of memory $\mathrm{T}$ cells within this mucosal tissue, an essential condition for safeguarding this site from respiratory pathogens.

\section{Methods}

Human blood and tissue samples. Spleen and lung samples were obtained from deceased organ donors. Spleen samples were obtained via DonateLife Victoria, while lung samples were obtained via the Alfred Hospital's Lung Tissue Biobank. PBMCs were isolated from buffy packs obtained from the Australian Red Cross Blood Service (ARCBS) (West Melbourne, Australia). As the clinical samples were obtained from organ donors, no data are available on whether/when donors were exposed to influenza virus infections. However, none of the donors died from an influenza virus infection. Furthermore, as the inactivated influenza virus vaccine, the only influenza vaccine available in Australia, does not elicit influenza virus-specific $\mathrm{CD} 8^{+} \mathrm{T}$ cell responses (T.H.O. Nguyen and K. Kedzierska, unpublished observations), prior vaccination history will not affect $\mathrm{CD}^{+} \mathrm{T}$ cell immunity to influenza virus.

Processing of peripheral blood and human tissues. PBMCs were isolated by Ficoll-Paque density-gradient centrifugation and cryopreserved. Mononuclear cells were isolated and cryopreserved from spleen and lungs by mechanical dissociation, followed by enzymatic digestion with $3 \mathrm{mg} / \mathrm{ml}$ of type III collagenase (Worthington Biochemical Corp.) and $100 \mathrm{mg} / \mathrm{ml}$ DNAse (Roche) in RPMI for 1 hour at $37^{\circ} \mathrm{C}$. Cells were forced through a $100-\mu \mathrm{m}$ strainer, and red blood cells were lysed prior to cryopreservation.

Ex vivo T cell proliferation. Lung CD8 ${ }^{+} \mathrm{T}$ cells were sort purified, labeled with CFSE, and cultured for 10 days with soluble anti-CD3 and $10 \mathrm{U} / \mathrm{ml} \mathrm{IL-2}$. In some experiments, cells were restimulated on day 10 after culture with PMA/ION for 5 hours in the presence of brefeldin A (BD GolgiPlug). 
$\mathrm{CD}^{103^{+} \mathrm{CD} 69^{+}}$
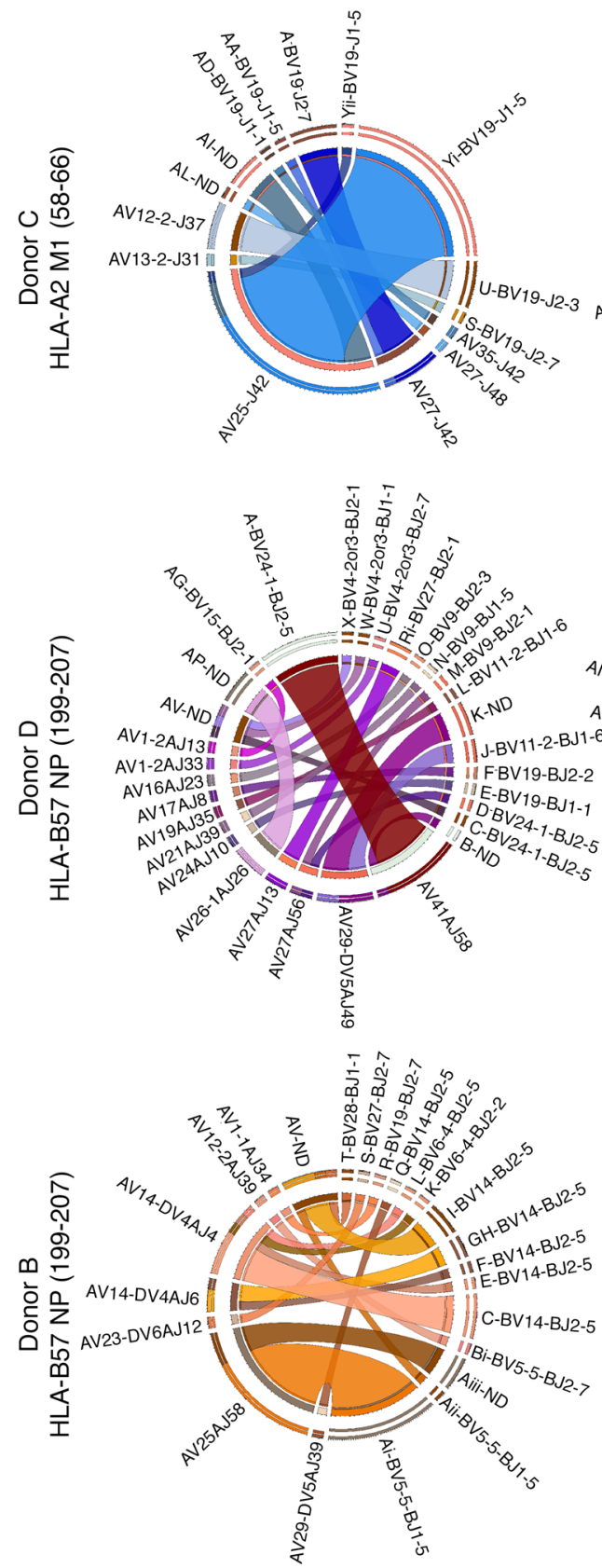

CD103-CD69
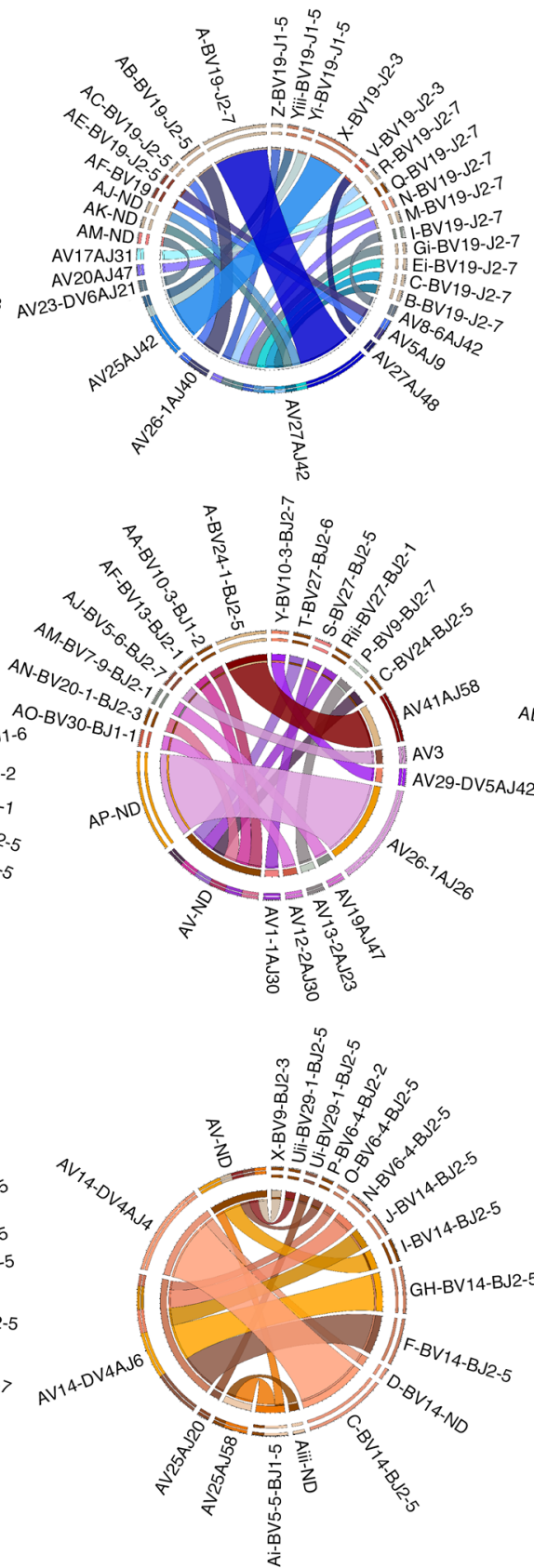

CD103-CD69-
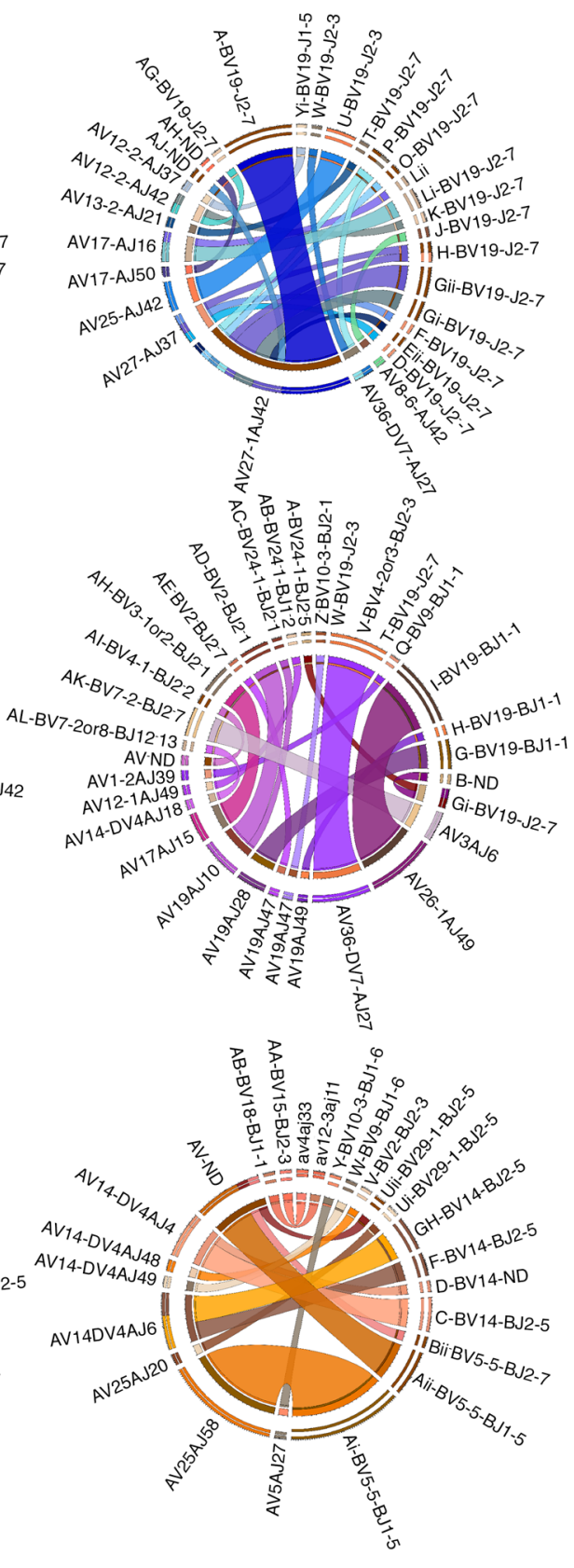

Figure 6. Shared TCR $\alpha \beta$ repertoire within lung Trm cells and CD103-CD69+ and CD103-CD69- subsets. Circos plots of frequencies of V $\beta-J \beta$ (BV) and V $\alpha-J \alpha$

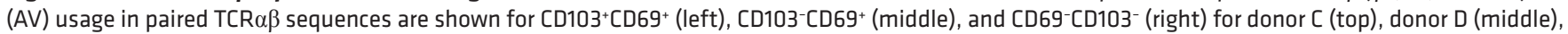
and donor B (bottom). Frequency of each unique clone is represented by the width of the band. In each donor band, colors across the 3 populations represent the same clone. Circos plots were generated with the Circos software package (38).

Ex vivo $T$ cell stimulation assay. Lung samples were thawed and stimulated with PMA/ION for 5 hours in the presence of brefeldin A (BD GolgiPlug and or GolgiSTOP). Cells were intracellularly stained for cytokine production using the BD Cytofix/Cytoperm kit following the manufacturer's instructions. For the measurement of CD107a, the anti-CD107a antibody was added to the samples for the duration of the stimulation.

Ex vivo virus stimulation assay. Stimulation with live virus was performed as described (7). Briefly, $1.5 \times 10^{6}$ mononuclear cells from human lung samples were thawed and infected at an MOI of 10 with influenza A (A/Puerto Rico/8 H1N1) for 1 hour at $37^{\circ} \mathrm{C}$. Cells were washed and incubated at $37^{\circ} \mathrm{C}$ for 3 hours in RPMI with $10 \%$ fetal calf serum, at which point brefeldin A (BD GolgiPlug) was added and cells were incubated for a further 18 hours. Cells were intracellularly stained for cytokine production and virus NP.

Flow cytometry. Cells were stained for 1 hour on ice with the appropriate mixture of $\mathrm{mAbs}$ and washed with $\mathrm{PBS}$ with $2 \% \mathrm{BSA}$. The following conjugated $\mathrm{mAbs}$ were obtained from $\mathrm{BD}$ Biosciences Pharmingen 
(anti-CD107a [H4A3], anti-granzyme B [GB11]), BioLegend (antiCD103 [Ber-ACT8], anti-CD8 [SK1], anti- CD69 [FN50], anti-CD28 [CD28.2], anti-IL-2 [MQ1-17H12], anti-IFN- $\gamma$ [4S.B3], anti-TNF- $\alpha$ [Mab11]) or eBioscience (anti-CD45RO [UCHL1], anti-CD3 [OKT3], anti-CD4 [OKT4], anti-perforin [B-D48], anti-IL-4 [MP4- 2502], and anti-IL-10 [JES3-9D7]). Tetramers were made in house from monomers provided by S. Gras and J. Rossjohn (Monash University). Staining was performed at room temperature for 1 hour.

Immunohistochemistry. Tissue was fixed in $4 \%$ paraformaldehyde for 6 hours on ice and embedded in OCT, and frozen sections $(14 \mu \mathrm{m})$ were cut using a cryostat. Tissue sections were acetone fixed, blocked in serum-free protein block, and stained with anti-CD3 (rabbit polyclonal, DAKO).

Single-cell reverse-transcriptase PCR and sequencing. Lung lymphocytes were stained with tetramers (either HLA-A2-M1 ${ }_{58-66}$, HLA-A3$\mathrm{NP}_{265-273}$, or HLA-B57-NP ${ }_{199-207}$ ) for 1 hour at room temperature, washed twice, then cell-surface stained with mAbs. Live $\mathrm{CD}^{+} \mathrm{CD}^{+}{ }^{+}$tetramer ${ }^{+}$ CD19-CD14- cells were individually sorted into 96-well Twin.tec PCR plates (Eppendorf) using a BD FACSAria III (BD Biosciences). Analysis of paired CDR3 $\alpha$ and CDR3 $\beta$ regions was performed by multiplex-nested reverse-transcriptase PCR before sequencing of TCR $\alpha$ and TCR $\beta$ products, as described $(16,35)$. Sequences were analyzed according to the IMGT/V-QUEST web-based tool $(36,37)$. Circos plots were generated using the Circos software package (38).

Statistics. Statistical analysis was carried out using GraphPad Prism software. Mann-Whitney $U$ test, Student's $t$ test, and 1-way or 2-way ANOVA were used where appropriate for comparison between 2 or multiple groups as indicated. Statistical significance was defined as $P<0.05$. Pearson correlation analyses were used and $r$ values stated where relevant.

Study approval. Human work was conducted according to the Australian National Health and Medical Research Council Code of Practice. Signed informed consent was obtained from all blood donors prior to the study. Tissues from deceased organ donors were obtained following written informed consent from the next of kin. The study was approved by the University of Melbourne Human Ethics Committee (IDs 1544553, 1443389, and 1441855), the Australian Blood Service Human Research Ethics Committee (2014\#14 and 2015\#8), and the ARCBS Ethics Committee (ID 17-07VIC-05).

\section{Author contributions}

AP, THON, and LMW designed the experiments. AP, LMW, SS, PGT, and THON performed the experiments and data analysis. JJ, GPW, TL, and SIM provided crucial clinical samples and reagents. GPW, KK, LMW, AP, and THON contributed to writing and editing of the manuscript.

\section{Acknowledgments}

We thank S. Gras and J. Rossjohn (Monash University) for monomers. This work was supported by the National Health and Medical Research Council of Australia (NHMRC) (to LMW), the CASS Foundation (to LMW), and a NHMRC program grant (1071916 to KK). SS is supported by the Victoria-India Doctoral Scholarship (VIDS) and the Melbourne International Fee Remission Scholarship (MIFRS), and KK is an NHMRC senior research level B fellow. SIM was supported by JDRF (JDRF 17-2011-527), NHMRC (GNT1123586) and the Operational Infrastructure Support Program of the Victorian Government. The Alfred Hospital's Lung Tissue Biobank is supported by the NHMRC Centre of Research Excellence (CRE) in Pulmonary Fibrosis

Address correspondence to: Linda M. Wakim or Katherine Kedzierska, Department of Microbiology and Immunology, University of Melbourne, The Doherty Institute for Infection and Immunity, Level 8 (L.M. Wakim), Level 7 (K. Kedzierska),792 Elizabeth Street, Melbourne, 3000, VIC, Australia. Phone: 61.3.9035.4141; Email: wakiml@unimelb.edu.au (L.M. Wakim). Phone: 61.3.8344.7962; Email:kkedz@unimelb.edu.au (K. Kedzierska).
1. Gao R, et al. Human infection with a novel avianorigin influenza A (H7N9) virus. N Engl JMed. 2013;368(20):1888-1897.

2. Braciale TJ. Immunologic recognition of influenza virus-infected cells. II. Expression of influenza A matrix protein on the infected cell surface and its role in recognition by cross-reactive cytotoxic $\mathrm{T}$ cells. J Exp Med. 1977;146(3):673-689.

3. Kees U, Krammer PH. Most influenza A virusspecific memory cytotoxic $\mathrm{T}$ lymphocytes react with antigenic epitopes associated with internal virus determinants. J Exp Med. 1984;159(2):365-377.

4. Yewdell JW, Bennink JR, Smith GL, Moss B. Influenza A virus nucleoprotein is a major target antigen for cross-reactive anti-influenza A virus cytotoxic T lymphocytes. Proc Natl Acad Sci U S A. 1985;82(6):1785-1789.

5. Quiñones-Parra S, et al. Preexisting CD8 ${ }^{+}$T-cell immunity to the H7N9 influenza A virus varies across ethnicities. Proc Natl Acad Sci US A. 2014;111(3):1049-1054.

6. van de Sandt CE, et al. Human cytotoxic T lymphocytes directed to seasonal influenza A viruses cross-react with the newly emerging H7N9 virus.
J Virol. 2014;88(3):1684-1693.

7. Wang Z, et al. Recovery from severe H7N9 disease is associated with diverse response mechanisms dominated by $\mathrm{CD}^{+} \mathrm{T}$ cells. Nat Commun. 2015;6:6833.

8. Wu T, et al. Lung-resident memory CD8 T cells (TRM) are indispensable for optimal crossprotection against pulmonary virus infection. JLeukoc Biol. 2014;95(2):215-224.

9. Wakim LM, Smith J, Caminschi I, Lahoud MH, Villadangos JA. Antibody-targeted vaccination to lung dendritic cells generates tissue-resident memory CD8 T cells that are highly protective against influenza virus infection. Mucosal Immunol. 2015;8(5):1060-1071.

10. Purwar R, Campbell J, Murphy G, Richards WG, Clark RA, Kupper TS. Resident memory T cells (T(RM)) are abundant in human lung: diversity, function, and antigen specificity. PLOS ONE. 2011;6(1):e16245.

11. Hombrink P, et al. Programs for the persistence, vigilance and control of human $\mathrm{CD}^{+}$ lung-resident memory T cells. Nat Immunol. 2016;17(12):1467-1478.

12. Mueller SN, Mackay LK. Tissue-resident memory
T cells: local specialists in immune defence. Nat Rev Immunol. 2016;16(2):79-89.

13. Pallett LJ, et al. IL-2high tissue-resident T cells in the human liver: Sentinels for hepatotropic infection. JExp Med. 2017;214(6):1567-1580.

14. Turner DL, et al. Lung niches for the generation and maintenance of tissue-resident memory $\mathrm{T}$ cells. Mucosal Immunol. 2014;7(3):501-510.

15. Sathaliyawala T, et al. Distribution and compartmentalization of human circulating and tissue-resident memory T cell subsets. Immunity. 2013;38(1):187-197.

16. Valkenburg SA, et al. Molecular basis for universal HLA-A ${ }^{*}$ 0201-restricted CD8 ${ }^{+}$T-cell immunity against influenza viruses. Proc Natl Acad Sci U S A. 2016;113(16):4440-4445.

17. Wakim LM, et al. The molecular signature of tissue resident memory CD8 T cells isolated from the brain. JImmunol. 2012;189(7):3462-3471.

18. Fernandez-Ruiz D, et al. Liver-resident memory $\mathrm{CD}^{+} \mathrm{T}$ cells form a front-line defense against malaria liver-stage infection. Immunity. 2016;45(4):889-902.

19. Pizzolla A, et al. Resident memory CD $8^{+}$ $\mathrm{T}$ cells in the upper respiratory tract prevent 
pulmonary influenza virus infection. Sci Immunol. 2017;2(12):pii.eaam6970.

20. Wakim LM, Gupta N, Mintern JD, Villadangos JA. Enhanced survival of lung tissue-resident memory $\mathrm{CD} 8^{+} \mathrm{T}$ cells during infection with influenza virus due to selective expression of IFITM3. Nat Immunol. 2013;14(3):238-245.

21. Muschaweckh A, et al. Antigen-dependent competition shapes the local repertoire of tissue-resident memory CD8 $8^{+} \mathrm{T}$ cells. J Exp Med. 2016;213(13):3075-3086.

22. Boyman O, Hefti HP, Conrad C, Nickoloff BJ, Suter M, Nestle FO. Spontaneous development of psoriasis in a new animal model shows an essential role for resident $\mathrm{T}$ cells and tumor necrosis factor-alpha. J Exp Med. 2004;199(5):731-736.

23. Cheuk S, et al. Epidermal Th22 and Tc17 cells form a localized disease memory in clinically healed psoriasis. JImmunol. 2014;192(7):3111-3120.

24. Clark RA. Resident memory T cells in human health and disease. Sci Transl Med. 2015;7(269):269rv1.

25. Messaoudi I, Guevara Patiño JA, Dyall R, LeMaoult J, Nikolich-Zugich J. Direct link between mhc polymorphism, $\mathrm{T}$ cell avidity, and diversity in immune defense. Science. 2002;298(5599):1797-1800.
26. Turner SJ, et al. Lack of prominent peptidemajor histocompatibility complex features limits repertoire diversity in virus-specific $\mathrm{CD} 8^{+} \mathrm{T}$ cell populations. Nat Immunol. 2005;6(4):382-389.

27. Price GE, Huang L, Ou R, Zhang M, Moskophidis D. Perforin and Fas cytolytic pathways coordinately shape the selection and diversity of $\mathrm{CD} 8^{+}-$ T-cell escape variants of influenza virus. J Virol. 2005;79(13):8545-8559.

28. Valkenburg SA, et al. Preemptive priming readily overcomes structure-based mechanisms of virus escape. Proc Natl Acad Sci U S A. 2013;110(14):5570-5575.

29. Kedzierska K, et al. Quantification of repertoire diversity of influenza-specific epitopes with predominant public or private TCR usage. J Immunol. 2006;177(10):6705-6712.

30. Gaide O, et al. Common clonal origin of central and resident memory $\mathrm{T}$ cells following skin immunization. Nat Med. 2015;21(6):647-653.

31. Kedzierska K, Venturi V, Field K, Davenport MP, Turner SJ, Doherty PC. Early establishment of diverse $T$ cell receptor profiles for influenza-specific CD8(+)CD62L(hi) memory T cells. Proc Natl Acad Sci USA. 2006;103(24):9184-9189.

32. Kedzierska K, La Gruta NL, Davenport MP, Turner SJ, Doherty PC. Contribution of T cell receptor affinity to overall avidity for virus-specific $\mathrm{CD}^{+} \mathrm{T}$ cell responses. Proc Natl Acad Sci U S A. 2005;102(32):11432-11437.

33. Cukalac T, et al. Reproducible selection of high avidity $\mathrm{CD} 8{ }^{+} \mathrm{T}$-cell clones following secondary acute virus infection. Proc Natl Acad Sci U S A. 2014;111(4):1485-1490.

34. Nguyen TH, et al. Maintenance of the EBVspecific $\mathrm{CD}^{+} \mathrm{TCR} \alpha \beta$ repertoire in immunosuppressed lung transplant recipients. Immunol Cell Biol. 2017;95(1):77-86.

35. Nguyen TH, et al. Recognition of distinct cross-reactive virus-specific $\mathrm{CD} 8^{+} \mathrm{T}$ cells reveals a unique TCR signature in a clinical setting. JImmunol. 2014;192(11):5039-5049.

36. Brochet X, Lefranc MP, Giudicelli V. IMGT/ V-QUEST: the highly customized and integrated system for IG and TR standardized V-J and V-D-J sequence analysis. Nucleic Acids Res. 2008;36(Web Server issue):W503-W508.

37. Folch G, Scaviner D, Contet V, Lefranc MP. Protein displays of the human $\mathrm{T}$ cell receptor alpha, beta, gamma and delta variable and joining regions. Exp Clin Immunogenet. 2000;17(4):205-215.

38. Krzywinski M, et al. Circos: an information aesthetic for comparative genomics. Genome Res. 2009;19(9):1639-1645. 